\title{
EXTRATROPICAL TROPOPAUSE TRANSITION LAYER CHARACTERISTICS FROM HIGH-RESOLUTION SOUNDING DATA
}

\author{
A Thesis \\ by \\ CAMERON ROSS HOMEYER
}

\author{
Submitted to the Office of Graduate Studies of \\ Texas A\&M University \\ in partial fulfillment of the requirements for the degree of \\ MASTER OF SCIENCE
}

May 2010

Major Subject: Atmospheric Sciences 


\title{
EXTRATROPICAL TROPOPAUSE TRANSITION LAYER CHARACTERISTICS FROM HIGH-RESOLUTION SOUNDING DATA
}

\author{
A Thesis \\ by \\ CAMERON ROSS HOMEYER
}

\author{
Submitted to the Office of Graduate Studies of \\ Texas A\&M University \\ in partial fulfillment of the requirements for the degree of \\ MASTER OF SCIENCE
}

Approved by:

Chair of Committee, Kenneth P. Bowman

Committee Members, Istvan Szunyogh

Steven F. DiMarco

Laura Pan

Head of Department, Kenneth P. Bowman

May 2010

Major Subject: Atmospheric Sciences 


\author{
ABSTRACT \\ Extratropical Tropopause Transition Layer Characteristics \\ from High-Resolution Sounding Data. (May 2010) \\ Cameron Ross Homeyer, B.S., Texas A\&M University \\ Chair of Advisory Committee: Kenneth P. Bowman
}

Accurate determination of the tropopause is important for applications such as dynamical analysis and forecasting, radiative transfer calculations, and the diagnosis of chemical transport in the atmosphere. In this paper, we examine how well the extratropical tropopause is determined in the National Centers for Environmental Prediction (NCEP) high-resolution Global Forecast System (GFS) model analysis over the continental United States using high-resolution aircraft and radiosonde data. The GFS analyses and sounding data compare well, with r.m.s. differences of approximately $600 \mathrm{~m}$, which is comparable to the vertical resolution of the model. The GFS tropopause is a good proxy in areas without in situ observations, but near the subtropical jet the GFS analysis often mistakenly identifies the secondary rather than the primary tropopause. We also explore an alternative method to identify the tropopause by fitting a smoothed step-function to the static stability profile. This new approach provides a measure of the depth of the troposphere-stratosphere transition and facilitates the study of the dynamical behavior of the tropopause region. In particular, using the transition depth, we are able to identify the statistical behavior of temperature in profiles with deep or shallow tropopause transition layers. 


\section{ACKNOWLEDGMENTS}

We acknowledge the START08 project for access to the aircraft data and motivation for this study, Geoff Manikin at NCEP for access to the GFS assimilations and tropopause code, and Steve Williams at the NCAR Earth Observing Laboratory for providing the radiosonde data. This research was funded by National Science Foundation grant ATM-072225 to Texas A\&M University. 
TABLE OF CONTENTS

CHAPTER

INTRODUCTION . . . . . . . . . . . . . . . . . . . 1

II

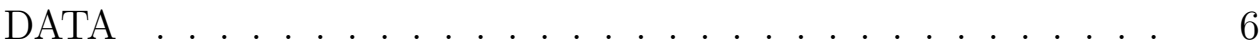

A. START08 Data ................... 6

B. Radiosonde Data . . . . . . . . . . . . 7

C. GFS Data . . . . . . . . . . . . . . . 8

III METHODS .................... 10

A. WMO Algorithm . . . . . . . . . . . . . . 10

B. Evaluation of Discretization Errors . . . . . . . . . 10

C. Curve-Fitting . . . . . . . . . . . . . . . 12

D. Spectral Analysis . . . . . . . . . . . . . . . 14

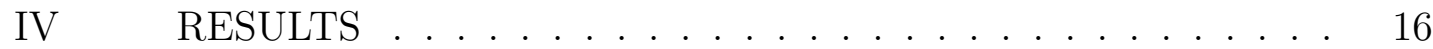

A. Sounding and Model Comparisons . . . . . . . . . . 16

B. Transition Layer Characteristics . . . . . . . . . . . . . 18

V SUMMARY AND DISCUSSION . . . . . . . . . . . 23

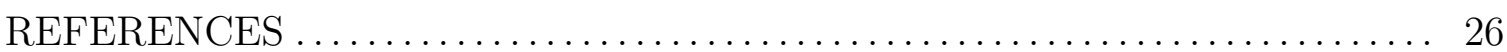

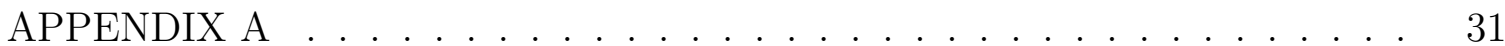

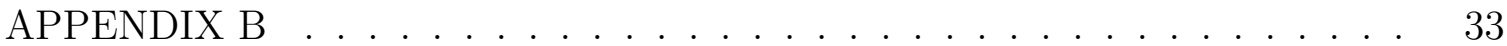

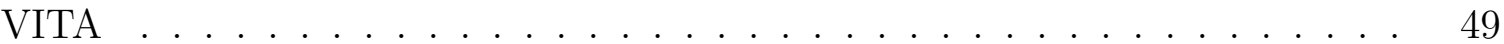




\section{LIST OF TABLES}

TABLE

I Statistics of tropopause comparison. The values given are root mean square differences $(\mathrm{m})$, mean differences $(\mathrm{m})$ of GFS - observations and slope $b$ of the least squares fit to a straight line and its $95 \%$ confidence interval for the tropopause height comparisons given in Figure 8. The statistics for the radiosonde comparison exclude those points within the gray ellipse of Figure 8b. . . . . . . 31

II Tropopause Characteristics by Latitude . . . . . . . . . . . . . . 32 


\section{LIST OF FIGURES}

FIGURE

1 Data representative of the U.S. Standard Atmosphere. Two profiles are present, temperature (solid) and the Brunt-Väisälä Frequency or static stability $N$ (dashed). . . . . . . . . .

Sample profiles of temperature for (a) START08 GV aircraft data and (b) radiosonde data. For each profile, an expanded view of the 11-12 km altitude range is given to show characteristics of the data. Profile (a) is from START08 Reasearch Flight 04 (RF04) for the time period 1830-1900 UTC on 2008-04-28. Profile (b) is from KABR (Aberdeen, South Dakota) at 00 UTC on 2008-06-20. . .

4 Map of radiosonde stations used from the continental United States.

$5 \quad$ Assuming an atmospheric temperature of $250 \mathrm{~K}:$ (a) $\mathrm{N}$ as a function of lapse rate and (b) maximum discretization error in $\mathrm{N}$ observed with radiosonde data. . . . . . . . . . . . . . . .

6 Two typical atmospheric profiles with temperature (left) and static stability (right) and corresponding hyperbolic tangent curve fits (gray). Profile (a) is an example of a sharp transition from troposphere to stratosphere, while profile (b) is broad. Profile (a) is from KGGW (Glasgow, Montana) and profile (b) is from KMFL (Miami, Florida). Observations are shown at $100 \mathrm{~m}$ sub-sampling. . .

$7 \quad$ Average power of Fourier Transforms of static stability $N$ as a function of wavelength for $\sim 200$ soundings from KAMA (Amarillo, TX) at full resolution (black) and $100 \mathrm{~m}$ sub-sampling (blue). The red curve is the power of the transform of a hyperbolic tangent function. The gray lines are 1-to-1 lines. . . . . . . . . . 
8 A scatterplot comparing GFS tropopause heights to observed lapserate tropopause heights for (a) START08 aircraft data and (b) Radiosondes. The 1-to-1 line is drawn in gray. For (a), profiles through stratospheric intrusions are marked by diamond plot symbols. For (b), the gray ellipse identifies the population where GFS analysis tropopause heights represent the secondary tropopause rather than primary. . . . . . . . . . . . . . . . . .

9 A vertical section of a GFS volume with corresponding map of the $300 \mathrm{hPa}$ wind field. The red line in the $300 \mathrm{hPa}$ wind map is the location of the section given. In the section, the lapse rate (color-fill) illustrates the thermal structure in the atmosphere; the orange dots represent application of the WMO definition to derive multiple tropopause heights; the orange line is the NCEP GFS output tropopause height calculated on the model grid; the purple contours are lines of constant potential vorticity; the black contours are wind speed and illustrate the vertical structure and extent of the subtropical jet. . . . . . . . . . . . . . . . .

10 An example profile from KCRP (Corpus Christi, Texas) where tropopause confusion in the GFS analysis is present. This profile is within the gray ellipse in Figure 8b. The GFS temperature and tropopause interpolated to the sonde location (dashed) and observed temperature and lapse-rate tropopauses (solid) are given. . 42

11 Distribution of lapse-rate tropopause pressure for all radiosondes. . .

12 Fraction of transition depths $\lambda$ in three latitude bands. . . . . . . . .

13 A scatterplot comparing the curve-fit tropopause and WMO lapserate tropopause heights for all radiosondes. The 1-to-1 line is drawn in black. Points are colored by the transition depth $\lambda$. . . . .

14 Transition depth $\lambda$ as a function of lapse-rate tropopause relative vorticity for all radiosondes. Points are colored by lapse-rate tropopause pressure. The black horizontal line indicates the division between large and small transition depths. . . . . . . . . . . . . 
FIGURE

15 Average temperature for $5^{\circ}$ wide latitude bands at relative altitude to the curve-fit tropopause. Two profiles for each band illustrate averages for large $(>2 \mathrm{~km}$, dashed) and small $(\leq 2 \mathrm{~km}$, solid) transition depths $(\lambda)$. The average lapse-rate and curve-fit tropopauses for large and small transition depths are also given in each plot. . . . . . . . . . . . . . . . . . . . . .

16 Normalized fraction of tropopause relative vorticity for large $(\lambda>$ $2 \mathrm{~km}$, dashed) and small $(\lambda \leq 2 \mathrm{~km}$, solid) transition depths for all radiosondes with lapse-rate tropopause pressure $p_{\text {trop }} \geq 200 \mathrm{hPa}$. 


\section{CHAPTER I}

\section{INTRODUCTION}

The concept of the tropopause as the boundary between two atmospheric layers with very different bulk properties - the troposphere and stratosphere - has proven to be useful in dynamic meteorology and atmospheric chemistry. The existence of the tropopause was discovered in the late nineteenth and early twentieth century. An extensive review of the history of tropopause discovery can be found in [1]. The long term variability and trends of the tropopause height have been recognized as a climate change indicator and they are under active investigations using both observations and models [e.g., 2, 3, 4].

The conventional definition of the tropopause is based on the temperature lapse rate, which relates directly to the static stability of the atmosphere. Idealized models of the tropopause usually assume a discrete jump in the static stability from relatively low values in the well-mixed troposphere to high values in the stable stratosphere. The static stability is usually represented by the Brunt-Väisälä frequency $N$ or its square, where

$$
N^{2}=\frac{g}{\theta} \frac{\partial \theta}{\partial z}=\frac{g}{T}\left(\frac{\partial T}{\partial z}+\Gamma_{d}\right)
$$

$g$ is the gravitational constant, $\theta$ is potential temperature, $T$ is temperature, $z$ is altitude, and $\Gamma_{d}=9.8^{\circ} \mathrm{C} \mathrm{km}^{-1}$ is the dry adiabatic lapse rate. The standard World Meteorological Organization (WMO) operational algorithm [5] for identifying the lapse-rate tropopause, discussed in more detail below, searches the temperature profile

The journal model is IEEE Transactions on Automatic Control. 
for layers that satisfy certain lapse-rate and thickness thresholds. In this thesis we will refer to this type of tropopause as the lapse-rate tropopause. It is also common to observe more than one tropopause in the atmosphere. Multiple tropopauses can be identified using the WMO algorithm (see Section IIIA). Second, third and even additional tropopauses are observed globally, most often in the midlatitudes $[6,7]$.

The U.S. Standard Atmosphere (USSA) is designed to be a representative 'average' profile of temperature, pressure, density and viscosity values at $45^{\circ} \mathrm{N}$ [8]. Figure 1 shows the USSA profiles of temperature and $N$ from the surface through the entire stratosphere. Temperature decreases with height in the troposphere and is isothermal or increasing with height in the stratosphere. The tropopause is clearly defined by the step change in $N$ from the troposphere to the stratosphere.

In recent years, the role of the tropopause as a chemical transport barrier and the detailed structure of the tropopause region have received increasing attention. The former is relevant to the quantification of stratosphere-troposphere exchange (STE) [e.g., 9]. The latter is most relevant to understanding the processes that form and maintain the tropopause [e.g., 10].

In the tropics, the thinking about the tropopause has moved away from the concept of a sharp boundary or a material surface toward a transition layer of finite depth between the troposphere and stratosphere. Observations support the idea that the tropopause itself is not a transport barrier. A broad layer with characteristics of both troposphere and stratosphere is commonly found and is referred to as the Tropical Tropopause Layer (TTL) [e.g., 11, 12, 13, 14].

In midlatitudes, the tropopause is typically much sharper than in the subtropics and it separates air masses with distinct chemical compositions. The sharp gradients of long-lived trace constituents indicate a minimum in transport or transport barrier at the tropopause. In addition to the lapse rate, potential vorticity (PV) and chemical 
tracers such as ozone have also been used to identify the tropopause [e.g., 15, 16, 17]. The chemical transition across the tropopause can be identified by chemical tracer correlations and characterized as a mixing layer of variable depth referred to as the Extratropical Transition Layer (ExTL) [e.g., 18, 19, 20, 21].

A Tropopause Inversion Layer (TIL) is frequently observed $[22,23]$ in temperature profiles immediately above the tropopause. The TIL is a layer $\sim 1$ to $2 \mathrm{~km}$ deep immediately above the lapse-rate tropopause that has very high stability (i.e., a negative lapse rate). When a TIL is present the tropopause is usually very sharp, with an abrupt transition between tropospheric and stratospheric lapse rates. Development and maintenance of the TIL is an area of ongoing research and it is not clear which processes are most important $[24,25]$. The relationship of the TIL and ExTL is also an area of ongoing research.

In this study we analyze the structure around the tropopause using temperature data from radiosondes, aircraft, and operational weather prediction models with a focus on the midlatitude tropopause. The results are presented in two parts. The first part characterizes the uncertainties in the tropopause representation in the National Centers for Environmental Prediction (NCEP) Global Forecast System (GFS) operational model analysis. The second part describes a new method for identifying the tropopause that characterizes the depth of the transition layer.

The first part of our analysis is motivated by the needs of transport studies using in situ or satellite remote sensing observations. In data analysis, the location of observations relative to the tropopause is often critical and the tropopause from operational weather prediction models or reanalyses is often used as the auxiliary information [e.g., 26, 21, 27]. It is important to understand the abilities of models to represent the structure of the tropopause region and the uncertainties introduced by the limited model resolutions. Therefore, the first part of this study is a comparison 
of the current NCEP GFS model tropopause analysis with high-resolution in situ measurements from aircraft and radiosondes. These comparisons are specifically motivated by the use of the GFS tropopause analysis in the Stratosphere-Troposphere Analyses of Regional Transport 2008 (START08) project [28]. The GFS tropopause has been used in the campaign phase for planning and conducting research flights, and is used in post campaign data analyses to quantify the chemical gradient across the tropopause under various meteorlogical conditions. Previous studies have compared tropopause heights in numerical models with observations [e.g., 29, 30]; but improvements in model capabilities and resolution, along with new in situ observations, suggest that further comparisons would be useful.

The second part of the analysis is motivated by the need to characterize the sharpness of the tropopause, in addition to its location, using the temperature field. Traditional tropopause analysis methods, like the WMO algorithm, typically identify the location of the tropopause but do not provide any information on the structure of the troposphere-to-stratosphere transition layer. Several analyses have described the sharpness of the tropopause in terms of vertical gradients in lapse-rate near the tropopause level $[17,31]$. In the second part of this study we explore an alternative method of characterizing the transition in atmospheric stability near the tropopause by fitting an idealized step-like analytical function (a hyperbolic tangent) to vertical profiles of static stability. This new approach gives additional information about the sharpness of the tropopause. In particular, one parameter derived from the curvefitting approach characterizes the depth of the troposphere-stratosphere transition in static stability. This new parameter is further used to identify profiles with shallow and deep tropopause transition layers (i.e., those with or without a TIL). The statistical behavior of profiles with different depths reveals that there is a relationship between the transition depth and the existence of a TIL. Our results also show that 
there are systematic variations in tropopause structure in relation to latitude and local dynamical processes. 


\section{CHAPTER II}

\section{DATA}

\section{A. START08 Data}

The START08 project took place from April to June 2008 [28]. The project was designed to make in situ measurements of meteorological, chemical, and microphysical properties of the extratropical upper troposphere and lower stratosphere (UT/LS). The NCAR/NSF Gulfstream V (GV) aircraft was used to target selected meteorological situations. These included tropospheric and stratospheric intrusions, gravity waves, and convection. A problem of particular interest to the project is the depth of the chemical and meteorological transition layer between the troposphere and stratosphere and its relationship to large-scale meteorological conditions.

During the project the GV aircraft flew 18 flights over North America and the Gulf of Mexico ranging from $\sim 25^{\circ}$ to $65^{\circ} \mathrm{N}$. Instruments onboard the aircraft measured standard meteorological parameters and a range of trace constituents including $\mathrm{O}_{3}$, $\mathrm{CO}, \mathrm{CO}_{2}, \mathrm{NO} / \mathrm{NO}_{y}$, and water vapor. Meteorological variables are sampled at 1 Hz. The resulting spatial resolution of the data depends on the aircraft velocity. At cruise altitude the horizontal resolution is $200-250 \mathrm{~m}$, while the vertical resolution is $\sim 7.5 \mathrm{~m}$ for a typical ascent/descent rate of $1500 \mathrm{ft} \mathrm{min}^{-1}$.

To identify tropopause crossings observed by the aircraft, the WMO tropopause definition is applied to the temperature measured by the aircraft as a function of altitude. Aircraft temperatures are reported with a precision of $0.006^{\circ} \mathrm{C}$ and accuracy $\pm 0.5^{\circ} \mathrm{C}$. From the 18 flights, 71 ascending or descending flight segments cross the tropopause and have a large enough vertical range to be used. It is important to note that horizontal motion during an individual ascending/descending flight segment can 
be quite large. Due to this horizontal travel, the ascending/descending flight legs are not true profiles and may sample different air masses. For simplicity, in the remainder of the paper we will refer to the selected ascending/descending flight segments as profiles. Figure $3 \mathrm{a}$ is a sample temperature profile from the GV aircraft. The inset shows an expanded view of the temperature profile near the tropopause. Some of the detailed structure, here and in other profiles, may be due to the horizontal motion of the aircraft. Errors related to the horizontal motion are discussed in Section IVA.

\section{B. Radiosonde Data}

National Weather Service (NWS) operational radiosondes are also analyzed. Over 8000 individual radiosondes profiles from April 1 - June 30, 2008 are used from 50 locations across the continental United States $\left(25-50^{\circ} \mathrm{N}\right)$. All radiosondes are part of the historic Weather Bureau Army-Navy (WBAN) station network. Radiosondes are typically available twice daily at 00 and 12 UTC and sometimes at 06 and/or 18 UTC. The vertical resolution of each radiosonde is $\sim 5 \mathrm{~m}$, which is close to that of the GV aircraft. Radiosonde temperatures are reported with a precision of $0.1^{\circ} \mathrm{C}$. This limits the ability to accurately compute lapse rates for small vertical scales; and, in fact, at full resolution the raw temperature profiles have a stepwise appearance (inset in Fig. 3b). For example, with the available precision of $0.1^{\circ} \mathrm{C}$ and vertical resolution of $10 \mathrm{~m}$, the error in the lapse rate due only to temperature discretization can reach $10^{\circ} \mathrm{C} \mathrm{km}^{-1}$. In order to minimize the effects of temperature discretization errors on the lapse rate calculation, we sub-sample the data to lower vertical resolution. Through varying the sampling depth we find that $100 \mathrm{~m}$ sampling reduces the discretization-induced noise substantially, while preserving most of the detailed structure of the temperature profile. Filtering the temperature profiles gives similar results. Additionally, when 
computing tropopause heights, only profiles that reach at least $20 \mathrm{~km}$ in altitude are used. The height of the primary tropopause is typically $<18 \mathrm{~km}$ everywhere while secondary tropopause heights can be well above $20 \mathrm{~km}$. The $20 \mathrm{~km}$ threshold is necessary for satisfactory performance of the WMO algorithm (see Section IIIA) and our curve-fitting method (see Section IIIC). The WMO algorithm is used to calculate the tropopause height from the observed radiosonde temperatures and altitudes.

\section{GFS Data}

The gridded analyses used in this study are produced by the NCEP Global Data Assimilation System (GDAS) as initial conditions for the high-resolution Global Forecast System (GFS) spectral model. The model's Gaussian grid has a longitude-latitude resolution of $0.3125^{\circ} \times \sim 0.3125^{\circ}(\sim 35 \mathrm{~km})$, with 64 hybrid sigma-pressure levels in the vertical ( $~ 500 \mathrm{~m}$ assuming equal spacing). GFS model output is provided by NCEP on a 47-level pressure grid via interpolation (or extrapolation, if necessary). The vertical resolution is $25 \mathrm{hPa}$ below the $100 \mathrm{hPa}$ level. The GFS model analyses are available four times daily at 00, 06, 12, and 18 UTC. For comparison with START08 aircraft data, GFS variables are linearly interpolated in time and space to each flight track. For comparison with radiosonde data, variables are interpolated in space only, at the nearest analysis time.

NCEP produces two-dimensional global gridded analyses of the tropopause height and pressure using the model's full internal grid resolution. The NCEP GFS tropopause algorithm adapts the WMO algorithm to the model's vertical grid. The second lapse rate criterion of the WMO algorithm is applied to the next three higher model levels. The vertical depth contained between the possible tropopause and third higher model level ranges from $1 \mathrm{~km}$ to $2 \mathrm{~km}$, which will vary somewhat from the $2 \mathrm{~km}$ depth 
criterion of the WMO algorithm (see Section IIIA). As a result, in the model the algorithm is often applied to a shallower layer than is the case with radiosonde data. 


\section{CHAPTER III}

\section{METHODS}

\section{A. WMO Algorithm}

In this study, we apply the WMO algorithm [5] following the guidelines set forth by the NWS and published by [32]. To avoid boundary layer inversions, the algorithm is applied only to altitudes above the $500 \mathrm{hPa}$ level. The tropopause is defined as the lowest altitude at which the temperature lapse rate decreases to $2^{\circ} \mathrm{C} \mathrm{km}^{-1}$, provided that the average lapse rate from this level to any point within the next higher $2 \mathrm{~km}$ does not exceed $2^{\circ} \mathrm{C} \mathrm{km}^{-1}$. The second requirement ignores shallow stable layers by specifying a minimum depth for the layer of increased stability air that is taken to be in the stratosphere. The flight of the observing system must also extend at least $2 \mathrm{~km}$ above the tropopause level. In the case of multiple tropopauses, the WMO outline states that if the lapse rate between any level at altitudes higher than a tropopause and all points within $1 \mathrm{~km}$ higher exceeds $3{ }^{\circ} \mathrm{C} \mathrm{km} \mathrm{km}^{-1}$, then additional tropopauses are defined using the same criterion above. We calculate lapse rates using a forward (upward) differencing scheme of the form $\Gamma\left(z_{i}\right)=-\partial T / \partial z \approx-\left(T_{i+1}-T_{i}\right) /\left(z_{i+1}-z_{i}\right)$ where $\Gamma$ is the lapse rate, $T$ is temperature, and $z$ is altitude.

\section{B. Evaluation of Discretization Errors}

As discussed in Section IIB, the radiosonde temperature data are reported with a precision of $0.1^{\circ} \mathrm{C}$. At the reported precision, the error of a measurement is assumed to be within $\pm 0.05^{\circ} \mathrm{C}$. It is important to consider this measurement error when evaluating derived quantities such as the lapse rate and quantifying the observed discretization error. Let us consider an example with a reference point $z_{i}$ and assume the worst case: 
a true isothermal layer with large measurement error. The observed temperature for the worst case is given by $T_{m}\left(z_{i}\right)=T\left(z_{i}\right)+0.05^{\circ} \mathrm{C}$ and $T_{m}\left(z_{i+1}\right)=T\left(z_{i+1}\right)-0.05^{\circ} \mathrm{C}$. The observed lapse rate can be given by $\Gamma_{m}=\Gamma+\Gamma_{\text {err }}$ where $\Gamma$ is the true lapse rate as in Section IIIA and $\Gamma_{e r r}$ is the observed discretization error. The observed discretization error in lapse rate is then given by

$$
\Gamma_{\text {err }}=\frac{0.05-(-0.05)}{\Delta z}=\frac{0.1}{\Delta z}\left[\mathrm{~K} \mathrm{~km}^{-1}\right]
$$

and is dependent on the vertical resolution $\Delta z$. For example, at full resolution $(\sim 10$ m) $\Gamma_{e r r}=10 \mathrm{~K} \mathrm{~km}^{-1}$. By sub-sampling to $100 \mathrm{~m}$, error is reduced to $\Gamma_{\text {err }}=1 \mathrm{~K}$ $\mathrm{km}^{-1}$.

In the curve-fitting method explored in this study (Section IIIC), we use static stability $N$. The static stability (Equation 1.1) is dependent upon the temperature and temperature lapse rate $\Gamma$. It is important to understand how the discretization error in lapse rate effects $N$ in order to optimize the curve-fitting result. Figure $5 \mathrm{a}$ shows $N$ as a function of lapse rate for a given atmospheric temperature of $250 \mathrm{~K}$. Figure $5 \mathrm{~b}$ shows the discretization error in $N$ given by $\Gamma_{e r r}$ as a function of vertical depth (or resolution) $\Delta z$. It is shown that the discretization error in $N$ decreases substantially as $\Delta z$ increases. This relationship between the error and vertical resolution is used to choose $100 \mathrm{~m}$ as a reasonable resolution to use to sub-sample the data. Sub-sampling trades off vertical resolution for reduced discretization error. Below $100 \mathrm{~m}$ the error in $N$ dramatically increases and above $100 \mathrm{~m}$ the reduction in error is small. 


\section{Curve-Fitting}

Because lapse rates in the stratosphere eventually become small or negative, and because the local variance of the temperature is normally not excessive, the WMO algorithm robustly finds a tropopause level under virtually all known conditions. The algorithm does not, however, provide information about the sharpness of the tropopause or the depth of the transition layer from troposphere to stratosphere. To obtain information about these characteristics of the tropopause, we take a different approach and fit an idealized smooth step-like function to observed profiles of static stability $N$ using a non-linear curve-fitting method. Our fitted function has the form

$$
N(z)=N_{\text {trop }}+\frac{N_{\text {strat }}-N_{\text {trop }}}{2}\left(1+\tanh \left(\frac{2\left(z-z_{0}\right)}{\lambda}\right)\right)
$$

where the asymptotic values of $N$ in the troposphere and stratosphere are $N_{\text {trop }}$ and $N_{\text {strat }}$, respectively; the tropopause level is taken to be the midpoint of the transition, $z_{0}$; and the full depth of the transition from the troposphere to the stratosphere is measured by $\lambda$. This functional form is used because it has a clearly defined length scale for the step width that is controlled by a single parameter, $\lambda$. Note that this functional form is symmetric around the tropopause and thus does not include a representation for the TIL. Including a TIL in the curve-fitting process would introduce additional adjustable parameters, and here our focus is on the largescale structure of the troposphere-stratosphere transition.

The values of the four parameters $N_{\text {trop }}, N_{\text {strat }}, z_{0}$, and $\lambda$ are calculated for each profile by using a Levenberg-Marquardt least-squares minimization method written by Craig Markwardt in Interactive Data Language (IDL) [33]. The algorithm converges to a fit by adjusting the function's parameters to minimize the sum of the squared 
residuals. Through trial and error we find the best initial guesses for the parameters to be $N_{\text {trop }}=0.0 \mathrm{~s}^{-1}, N_{\text {strat }}=25.0 \cdot 10^{-3} \mathrm{~s}^{-1}$, and $\lambda=1 \mathrm{~km}$. The initial guess for the tropopause level $z_{0}$ is taken to be the value produced by the WMO algorithm.

As with the lapse rate $\Gamma, N^{2}$ is calculated using forward (upward) differences. Points with $N^{2}<0$ are omitted in the curve fitting procedure. These points are rare and tend to occur in the lower troposphere. We neglect moisture effects in $N$ by using the physical temperature in our observations.

As was recognized when the U.S. Standard Atmosphere was defined (Figure 1), secondary and tertiary jumps in static stability occur commonly in the stratosphere (see also [6]). The existence of multiple steps could cause the curve-fitting algorithm to converge to the wrong step. To help avoid this problem, we use only data at altitudes up to $20 \mathrm{~km}$. Using the WMO tropopause as the initial guess also helps the fitting procedure converge to the primary tropopause. For START08 flight data, an additional constraint is used: values of $N>50 \cdot 10^{-3} \mathrm{~s}^{-1}$ are ignored. These values occur when profiles are obtained during ascents or descents with long horizontal distances, typically observed in $5-10 \%$ of a profile. We test the sensitivity of the curve-fitting algorithm to boundary layer inversions. Omitting the boundary layer does not significantly change the results. However, it can cause the curve-fit to fail in some cases by eliminating too much of the low stability tropospheric layer. For our analysis we include the boundary layer in all profiles.

Figure 6 shows the data and the results of the curve fitting procedures for two radiosonde profiles: one with a sharp transition and a TIL (a) and one with a broad transition (b). The fitted hyperbolic tangent function is superimposed on $N$ in gray. As can be seen, the curve-fitting algorithm adjusts the functional parameters, notably $\lambda$, to follow the observed transition. The tropopause levels from the WMO algorithm and curve-fitting process agree well for profiles with sharp transitions (small $\lambda$ ). For 
profiles that have a broad transition, however, the tropopause level from the curve fits, which we take to be the midpoint of the hyperbolic tangent function, are biased low by about $1 \mathrm{~km}$ relative to the values from the WMO algorithm. This results from the fact that the secondary lapse-rate condition in the WMO algorithm is only satisfied toward the top of the transition layer when the stability transition is smooth and broad.

\section{Spectral Analysis}

In addition, and prior to our evaluation of discretization error, we explored the scaledependent variability of the observed static stability $N$ by using spectral analysis. This approach is motivated by assuming our idealized curve-fitting function (hyperbolic tangent) is a true representation of the atmosphere. If the power of the observed spectra have peaks at short wavelengths, we can use a filter to remove high-frequency noise and more effectively locate the tropopause. Figure 7 shows the power (square of spectra) of the average transform of static stability $N$ as a function of wavelength for $\sim 200$ soundings from KAMA (Amarillo, TX). The black line is the average power at full resolution, the blue is the average at $100 \mathrm{~m}$ sub-sampling and the red is the power of an idealized hyperbolic tangent. The data at full resolution and $100 \mathrm{~m}$ sub-sampling are first interpolated to an evenly spaced $5 \mathrm{~m}$ vertical grid for Fourier analysis. The noise introduced by the discretization error is well illustrated in the full resolution average at wavelengths less than $50 \mathrm{~m}$. When sub-sampling is introduced, the average agrees well with the idealized curve at short and long wavelengths. At wavelengths between $100 \mathrm{~m}$ and $1000 \mathrm{~m}$ the data exhibit power an order of magnitude higher than the idealized curve. This feature is representative of real physical variability in the lapse rate. Based on these spectra we conclude that it is not pos- 
sible to separate noise from real physical variability, but that sub-sampling to 100 $m$ resolution effectively removes errors due to temperature discretization at small scales. Although sub-sampling can introduce aliases in the data, we observed the same qualitative result using a simple, low-pass filter at $100 \mathrm{~m}$ wavelength. 


\section{CHAPTER IV}

\section{RESULTS}

\section{A. Sounding and Model Comparisons}

We first compare tropopause heights computed by applying the WMO algorithm to the high-resolution aircraft and radiosonde data with the gridded GFS tropopause analysis. Figure 8 contains scatterplots of the GFS tropopause heights as a function of the (a) GV and (b) radiosonde altitudes. Because the aircraft ceiling is around $14 \mathrm{~km}$, there are no GFS-GV comparisons for subtropical or tropical conditions that have high tropopause heights. This situation occurs quite commonly in the radiosonde database, however, with some tropopause heights near $19 \mathrm{~km}$. For both data sets, the majority of the points lie near the 1-to-1 line. Statistics of the comparisons are given in Table I. The statistics for the GFS-Radiosonde comparison do not include the points within the gray ellipse in Figure 8b. The root mean square differences between the in situ observations and the gridded analysis are $\sim 600 \mathrm{~m}$. These values are comparable to the resolution of the GFS vertical grid, which is $\sim 500 \mathrm{~m}$. The mean difference for the GFS-GV comparison is small suggesting that there is no significant bias. For the GFS-Radiosonde comparison, the mean difference is -75 $\mathrm{m}$ suggesting that the GFS analysis slightly underestimates the observed tropopause in radiosonde observations.

In the GV aircraft comparison (Fig. 8a), the largest differences are seen in profiles flown through stratospheric intrusions (tropopause folds). Stratospheric intrusions are typically long and narrow depressions in tropopause height [e.g., 34]. Within the region of a stratospheric intrusion, determining the tropopause is a tough task for a numerical model. Moreover, interpolating a surface that has steep gradients or even 
multiple values due to folding of the material surface can result in large errors. As discussed in Section IIA, sampling different air masses in a profile (likely the case when flying through stratospheric intrusions) can result in inconsistencies in lapse rates. Because of these predicaments, it is nearly impossible to avoid significant differences between observations and model analyses near stratospheric intrusions. Otherwise, the differences between observed tropopause heights and analysis heights are reasonably small.

In the radiosonde comparison (Fig. 8b) there are two distinct populations. The majority lie close to the 1-to-1 line and have errors comparable to the vertical resolution of the model. A second population, however, has GFS tropopause heights substantially higher than the radiosonde values (gray ellipse, $7.5 \%$ of the total population). These large differences typically occur near the subtropical jet. A large break from tropical $(15-18 \mathrm{~km})$ to mid-latitude tropopause heights $(10-12 \mathrm{~km})$ is normally observed close to the subtropical jet [e.g., 35, 36, 6]. A latitude-height section through an observed tropopause break is shown in Figure 9. In the inset map, $300 \mathrm{hPa}$ geopotential height and wind speed show the location of the jet, while the red line shows the location of the cross section. Along this section south of $35^{\circ}$ the uncertainty in the GFS tropopause location is large due both to the low vertical resolution of the model and the weakness of the stability, in comparison to the stratosphere, above the primary tropopause. As a result, the GFS tropopause algorithm, which identifies only a single tropopause, (solid orange line) jumps between the primary (lower) and secondary (upper) tropopauses in the latitude range between about 22 and $37^{\circ}$. This includes regions both north and south of the subtropical jet. Applying the WMO algorithm to the model output (orange dots) gives similar results and identifies multiple tropopauses at some locations. In the presence of multiple tropopauses, the GFS analysis often selects the secondary tropopause near the subtropical jet. Profiles 
in that region tend to have complicated stability structures through the tropopause level. In such cases, the primary tropopause is often easier to identify in higher resolution radiosonde data. An example of this is shown in Figure 10. The primary tropopause is well defined in the radiosonde data by a strong inversion between $\sim 12$ and $14 \mathrm{~km}$. In the GFS profile the inversion is almost entirely lost, which prevents its detection by the WMO algorithm. In cases where the GFS analysis misses the primary tropopause, we test the importance of resolution by linearly interpolating the radiosonde profiles to the GFS model resolution. Despite the reduced vertical resolution, the primary tropopause is still correctly identified in the radiosonde data. This suggests that resolution alone is not responsible for this error, and that either internal model processes or the data assimilation process are further smoothing the observed temperature profile. [23] found that the horizontal to vertical aspect ratio of large-scale dynamics in operational models is not appropriate in the extratropical tropopause region. Birner suggests that a resolution of at least $400 \mathrm{~m}$ in the tropopause region is needed to reasonably model the observed stability structure in operational models with $100 \mathrm{~km}$ horizontal resolution.

\section{B. Transition Layer Characteristics}

To evaluate the characteristics of the troposphere to stratosphere transition layer, we apply the curve-fitting method discussed in Section IIIC to the entire radiosonde and aircraft data set. We present results here only for the radiosonde data. The aircraft data results are similar. Figure 11 shows the distribution of lapse-rate tropopause pressure, $p_{\text {trop }}$, in the radiosonde observations. There are two peaks present, a subtropical peak with high tropopauses near $100 \mathrm{hPa}$ and a midlatitude peak with pressures centered around $200 \mathrm{hPa}$. This bimodal structure is observed in previous studies 
[e.g., 20, 6, 37]. The minimum occurrence between the two modes is at $\sim 135 \mathrm{hPa}$ $(\sim 14 \mathrm{~km}$ as in [20]) in these observations.

Figure 12 shows the frequency of occurrence of different transition depths $\lambda$ within three $5^{\circ}$ latitude bands. In the $25^{\circ}-30^{\circ} \mathrm{N}$ band (black), there is significant bimodality with a minimum occurrence near $2 \mathrm{~km}$. Higher latitude bands have a substantially larger fraction of sharp transitions $(\lambda<0.5 \mathrm{~km})$. Based on these results we divide all profiles into small $(\lambda \leq 2 \mathrm{~km})$ and large $(\lambda>2 \mathrm{~km})$ transition depths. The $77 \%$ of the profiles with $\lambda \leq 2 \mathrm{~km}$ have an average depth of $415 \mathrm{~m}$, indicating predominantly very sharp tropopause transitions. The $21 \%$ with large transition depths, on the other hand, have an average $\lambda$ of $5.8 \mathrm{~km}$. In the remaining $2 \%$ of profiles, the curve-fitting algorithm failed to identify a tropopause within the available profile. Figure 13 compares curve-fit tropopause heights to lapse-rate tropopause heights for the radiosonde data. The two tropopause estimates agree well when the tropopause is sharp (small $\lambda$, indicated by gray points). As noted earlier, the curve-fits are biased low relative to the lapse-rate tropopause, particularly when the transition is broad. This tendency is well illustrated in Figure 13. Those profiles with $\lambda>2$ km (black points) have r.m.s. differences of $1.75 \mathrm{~km}$. Profiles with sharp transitions $(\lambda \leq 2 \mathrm{~km})$ have r.m.s. differences of $780 \mathrm{~m}$. Outliers with significantly lower curvefit tropopauses and sharp transitions occur where the curve-fitting method converges to a shallow mid-tropospheric inversion layer that does not satisfy the WMO $2 \mathrm{~km}$ criterion.

The occurrence of different tropopause heights and transition layer depths varies strongly with latitude. Table II lists the fraction of large transition depths and fraction of high lapse-rate tropopauses $(\mathrm{P}<135 \mathrm{hPa})$ as a function of latitude. Large transition depths dominate at low latitudes, which also have high tropopauses, while the reverse is true at higher latitudes. 
The dominance of deep transition layers in the subtropics can be attributed to the characteristics of the tropical upper troposphere [14], but it does not explain the presence of all large values of $\lambda$ that occur at latitudes north of the sub-tropical jet. [17] suggested that large transition depths in midlatitudes occur in areas of cyclonic flow in the lower stratosphere. In their hypothesis, if potential vorticity is conserved, increasing cyclonic vorticity must be balanced by column stretching. As the column stretches, the lapse rate $\Gamma$ increases, becoming more tropospheric, and the depth of the transition layer increases. Additionally, the column stretching causes air below to descend and warm, decreasing lapse rates in the mid-troposphere and further deepening the transition. [38] used a simple model to show that the jump in static stability at the tropopause is much weaker in cyclonic flow. Also, in Figure 4 of [24] the observed amplitude of the TIL is significantly weaker in the presence of cyclonic flow in the upper troposphere $(200 \mathrm{hPa})$. In order to evaluate this effect, we interpolate GFS relative vorticity to the radiosonde tropopause locations. Figure 14 shows the transition depth $\lambda$ as a function of tropopause relative vorticity. Points are colored by tropopause pressure to illustrate their locations. Subtropical profiles with high tropopauses (red) have, on average, slightly negative relative vorticity at all transition depths which is consistent with locations on the anticyclonic side of the jet. Subtropical tropopauses also have a large portion of their population at large transition depths, in agreement with Table II. Mid-latitude profiles with low tropopauses (blue) can have cyclonic or anti-cylonic flow when the transition depths are small. Those with large transition depths (upper right quadrant), however, are dominated by positive relative vorticity. This is in agreement with previous studies. Our results suggest that there are indeed two types of deep troposphere-stratosphere transition layers. In the subtropics the deep transitions are characteristic of the tropical upper troposphere. At higher latitudes deep transitions are the result of 
enhanced cyclonic vorticity in the lower stratosphere.

Following [23] we average the temperature profiles relative to the tropopause, but stratify the data by $\lambda$ (Fig. 15). In all latitude zones the composite profiles for sharp tropopauses $(\lambda \leq 2 \mathrm{~km}$, solid lines) have an obvious TIL with a depth between $\sim 1$ and $2 \mathrm{~km}$. The TIL becomes more pronounced with increasing latitude, similar to the results in [39]. Above the TIL the mean lapse rates are small but positive, at least up to $5 \mathrm{~km}$ above the tropopause. The composites for profiles with $\lambda>2 \mathrm{~km}$ (dashed lines) transition smoothly from positive to negative lapse rates through a relatively deep layer (i.e., no presence of TIL) at latitudes $<40^{\circ}$. Differences in mean lapse-rate tropopause height between profiles with large and small transition depths at those latitudes are large $(\sim 1.5 \mathrm{~km})$. Higher tropopauses and large transition depths are typical of the tropical upper troposphere as a zone of deep transitions in stability. At latitudes $>40^{\circ}$, the composites for profiles with $\lambda>2 \mathrm{~km}$ transition smoothly from positive to near isothermal lapse rates through a relatively deep layer and there is no TIL. The mean lapse-rate tropopause difference between profiles with large and small transition depths also becomes small at latitudes $>45^{\circ}$. As was shown previously, large transition depths in the midlatitudes are the result of cyclonic stretching and warming in the lower stratosphere. This inferred structure can be seen at the highest latitudes for large transition depths. These results also indicate that the curve-fitting algorithm is indeed successful at measuring the transition layer depth.

When midlatitude profiles with small transition depths are partitioned by the sign of the vorticity at the tropopause, the results agree with Figure 4 of [24]. For these sharp transitions, the amplitude of the TIL is larger in anti-cyclonic flow and smaller in cyclonic flow. Figure 16 shows the normalized fraction of small and large transition depths for purely extratropical profiles $\left(p_{\text {trop }} \geq 200 \mathrm{hPa}\right)$ as a function of tropopause relative vorticity. The proportions of sharp and broad transition depths 
for these purely extratropical profiles are $95 \%$ and $5 \%$, respectively. There is large overlap in the vorticity distributions for large and small transitions illustrating that the sign and magnitude of vorticity alone does not determine the sharpness of a transition. It is not clear from our analysis what additional conditions are present when $\lambda$ becomes greater than $2 \mathrm{~km}$. It is obvious, however, that decreased sharpness of the tropopause is related to cyclonic flow. The results from [38] suggest that these deep transitions are more likely toward the center of a cyclone.

The presence of two characteristically different thermal structures in midlatitudes adds additional detail to the [23] result. Birner used temperatures from highresolution radiosondes north of $41.5^{\circ} \mathrm{N}$ latitude to demonstrate the presence of the TIL above the lapse-rate tropopause. He concluded that the Standard Atmosphere temperature profile should be updated to include the presence of the TIL. In our analysis we find that there are two main types of extratropical temperature profiles. Sharp transitions with a TIL are observed $\sim 90 \%$ of the time (see Table II) at the latitudes explored in [23]. The remaining 10\% tend to have smooth and deep transition layers between the troposphere and stratosphere. If all profiles are averaged together, the signature of profiles with smooth transitions is lost. 


\section{CHAPTER V}

\section{SUMMARY AND DISCUSSION}

Comparisons of in situ observations of the lapse-rate tropopause by radiosondes and the NCAR GV aircraft with the NCEP GFS operational forecast model analysis show generally good agreement when using the WMO tropopause algorithm. R.m.s. differences between observations and the model analyses are $\sim 600 \mathrm{~m}$, which is close to the vertical resolution of the current GFS operational model. These differences serve as a representation of the uncertainty in the tropopause height for use in trace gas analysis at relative altitude to the tropopause. There is, however, a significant population of soundings with model tropopauses up to $5 \mathrm{~km}$ higher than the radiosonde tropopauses (Fig. 8b). In these cases, which mostly occur near the tropopause break around the subtropical jet, the layered stability structure and the vertical resolution of the model limits its ability to represent the structure of the temperature profile correctly. The smooth temperature profile in the model does not satisfy the WMO tropopause definition at the primary tropopause level, and the GFS analysis mistakenly identifies the secondary tropopause as the primary. This tropopause misidentification occurs in less than $10 \%$ of the soundings for the radiosonde stations used in this study. Correcting these errors will require improving the model representation of the structure of the upper troposphere and lower stratosphere (UT/LS), likely beginning with increased vertical resolution. Increased horizontal resolution will also help in situations where the tropopause is highly deformed. For aircraft missions the GFS operational meteorological analyses provide a way to extend the tropopause analysis to wide geographic areas with good confidence, although care should be taken to identify cases near the tropopause break where the model analysis may jump between the primary and secondary tropopauses (e.g., Fig. 9). 
This study also analyzed the structure of the static stability near the tropopause by using a Levenberg-Marquardt minimization algorithm to fit a hyperbolic tangent function to radiosonde profiles of Brunt-Väisälä frequency $N(z)$. The parameters of the fitted function include the location of the tropopause $\left(z_{0}\right)$ and the depth of the transition layer between the troposphere and stratosphere $(\lambda)$. Based on the results of this analysis of radiosondes from the continental United States, we find that tropopauses can be divided into high and low tropopauses ( $p_{\text {trop }}$ less than or greater than $135 \mathrm{hPa}$ ) and into sharp and broad tropopause transition layers ( $\lambda$ less than or greater than $2 \mathrm{~km}$ ). Equatorward of the tropopause break the tropopause is high $\left(p_{\text {trop }}<135 \mathrm{hPa}\right)$. Due to variations in the position of the jet these high tropopauses, which are characteristic of tropical and subtropical air, are found well into the midlatitudes. Static stability profiles in these cases tend to have deep transitions layers (large $\lambda$ ), characteristic of the subtropical upper troposphere. About $40 \%$ of soundings between $25^{\circ}$ and $30^{\circ} \mathrm{N}$ have sharp tropopauses. As the latitude increases the fraction of profiles with high tropopauses decreases rapidly. Extratropical tropopauses typically have pressures greater than $135 \mathrm{hPa}$, with a relatively long tail toward higher pressure (Fig. 11). Extratropical tropopauses are much more likely to be sharp $(\operatorname{small} \lambda)$ and to have a TIL, but there is a significant population with large values of $\lambda$. These tend to occur when there is positive relative vorticity at the tropopause, in agreement with the column stretching process [17, 38, 24].

Categorizing the temperature profiles by $\lambda$ and compositing them with respect to the tropopause height produces a dominant extratropical temperature profile similar to that found by Birner [23], with a pronounced TIL, and a second, smaller population with a deep, smooth tropopause transition layer. The amplitude of the TIL increases with latitude for profiles with sharp tropopauses. These variations should be kept in mind when using reference profiles such as the U.S. Standard Atmosphere. 
Our curve-fitting method allows us to quantify the less common, deep stability transition cases for the first time, extending the results from [23] and [39]. The mean of all profiles (as seen in [23]) gives the impression that the TIL is always present in midlatitudes. We have shown, however, that there are three characteristic types of transition layers observed: sharp transitions with a TIL, broad transitions from positive to negative lapse-rates, and broad transitions from positive to near isothermal lapse-rates. The most common midlatitude profiles have a sharp transition with a TIL. The relationship between both sharp and broad transitions and relative vorticity at the tropopause has also been shown. Although midlatitude broad tropopause transitions are found to be related to cyclonic flow, the sharpness of the tropopause cannot be explained by the magnitude and sign of relative vorticity alone (see Figures 14 \& 16). Additional analysis is underway to investigate whether the sharpness of the lapse-rate tropopause is related to the depth of the chemical transition layer by using trace species such as ozone and carbon monoxide. 


\section{REFERENCES}

[1] K. P. Hoinka, "The tropopause: discovery, definition and demarcation," Meteorol. Zeitschrift, vol. 6, pp. 281-303, 1997.

[2] D. J. Seidel and W. J. Randel, "Variability and trends in the global tropopause estimated from radiosonde data," J. Geophys. Res., vol. 111, no. D21101, pp. $1-17,2006$.

[3] S-W. Son, L. M. Polvani, D. W. Waugh, T. Birner, H. Akiyoshi, R. R. Garcia, A. Gettelman, D. A. Plummer, and E. Rozanov, "The impact of stratospheric ozone recovery on tropopause height trends," J. Climate, vol. 22, pp. 429-445, 2009.

[4] A. Gettelman, M. I. Hegglin, S-W. Son, J. Kim, M. Fujiwara, et al., "Multimodel assessment of the upper troposphere and lower stratosphere: tropics and trends," J. Geophys. Res., vol. In Review, pp. 1-62, 2010.

[5] WMO, "Meteorology - a three-dimensional science: Second session of the commission for aerology," WMO Bulletin, vol. IV, no. 4, pp. 134-138, 1957.

[6] W. J. Randel, D. J. Seidel, and L. L. Pan, "Observational characterisitics of double tropopauses," J. Geophys. Res., vol. 112, no. D07309, pp. 1-13, 2007a.

[7] J. A. Añel, J. C. Antuña, L. de la Torre, J. M. Castanheira, and L. Gimeno, "Climatological features of global multiple tropopause events," J. Geophys. Res., vol. 133, no. D00B08, pp. 1-14, 2008.

[8] NOAA, NASA, and U. S. Air Force, "U.S. standard atmosphere 1976, technical report," U.S. Govt. Printing Office, Washington, D.C., 1976. 
[9] J. R. Holton, P. H. Haynes, M. E. McIntyre, A. R. Douglass, and L. Pfister, "Stratosphere-troposphere exchange," Rev. Geophys., vol. 33, no. 4, pp. 403439, 1995.

[10] P. Haynes, J. Scinocca, and M. Greenslade, "Formation and maintenance of the extratropical tropopause by baroclinic eddies," Geophys. Res. Lett., vol. 28, no. 22, pp. 4179-4182, 2001.

[11] S. C. Sherwood and A. E. Dessler, "A model for transport across the tropical tropopause," J. Atmos. Sci., vol. 58, pp. 765-779, 2000.

[12] J. R. Holton and A. Gettelman, "Horizontal transport and the dehydration of the stratosphere," Geophys. Res. Lett., vol. 28, no. 14, pp. 2799-2802, 2001.

[13] A. Gettelman and T. Birner, "Insights into tropical tropopause layer processes using global models," J. Geophys. Res., vol. 112, no. D23104, pp. 1-15, 2007.

[14] S. Fueglistaler, A. E. Dessler, T. J. Dunkerton, I. Folkins, Q. Fu, and P. W. Mote, "Tropical tropopause layer," Rev. Geophys., vol. 47, no. RG1004, pp. $1-31,2009$.

[15] R. J. Reed, "A study of a characteristic type of upper-level frontogenesis," J. Meteor., vol. 12, pp. 226-237, 1955.

[16] M. A. Shapiro, "Turbulent mixing within tropopause folds as a mechanism for the exchange of chemical constituents between the stratosphere and troposphere," J. Atmos. Sci., vol. 37, pp. 994-1004, 1980.

[17] S. Bethan, G. Vaughan, and S. J. Reid, "A comparison of ozone and thermal tropopause heights and the impact of tropopause definition on quantifying the 
ozone content of the troposphere," Q. J. R. Meteorol. Soc., vol. 122, pp. 929-944, 1996.

[18] WMO, "Wmo scientific assessment of ozone depletion," WMO Global Ozone Res. Monit. Proj. Rep., vol. 47, pp. 498, 2003.

[19] A. Zahn and C. A. M. Brenninkmeijer, "New directions: A chemical tropopause defined," Atmos. Environ., vol. 37, pp. 439-440, 2003.

[20] L. L. Pan, W. J. Randel, B. L. Gary, M. J. Mahoney, and E. J. Hintsa, "Definitions and sharpness of the extratropical tropopause: A trace gas perspective," J. Geophys. Res., vol. 109, no. D23103, pp. 1-11, 2004.

[21] M. I. Hegglin, C. D. Boone, G. L. Manney, and K. A. Walker, "A global view of the extratropical tropopause transition layer from atmospheric chemistry experiment fourier transform spectrometer o-3, h2o, and co," J. Geophys. Res., vol. 114, no. D00B11, pp. 1-18, 2009.

[22] T. Birner, A. Dörnbrack, and U. Schumann, "How sharp is the tropopause at midlatitudes?," Geophys. Res. Lett., vol. 29, no. 14, pp. 1-4, 2002.

[23] T. Birner, "Fine-scale structure of the extratropical tropopause," J. Geophys. Res., vol. 111, no. D04104, pp. 1-14, 2006.

[24] W. J. Randel, F. Wu, and P. Forster, "The extratropical tropopause inversion layer: Global observations with gps data, and a radiative forcing mechanism," J. Atmos. Sci., vol. 64, pp. 4489-4496, 2007 b.

[25] S.-W. Son and L. M. Polvani, "Dynamical formation of an extra-tropical tropopause inversion layer in a relatively simple circulation model," Geophys. Res. Lett., vol. 34, no. L17806, pp. 1-5, 2007. 
[26] L. L. Pan, K. P. Bowman, M. Shapiro, W. J. Randel, R. S. Gao, T. Campos, C. Davis, S. Schauffler, B. A. Ridley, J. C. Wei, and C. Barnet, "Chemical behavior of the tropopause observed during the stratosphere-troposphere analyses of regional transport experiment," J. Geophys. Res., vol. 112, no. D18110, pp. $1-13,2007$.

[27] A. E. Dessler, "Clouds and water vapor in the northern hemisphere summertime stratosphere," J. Geophys. Res., vol. 114, no. D00H09, pp. 1-7, 2009.

[28] L. L. Pan, K. P. Bowman, E. Atlas, S. C. Wofsy, F. Zhang, et al., "The stratosphere-troposphere analyses of regional transport 2008 (start08) experiment," Bull. Amer. Meteor. Soc., vol. In Press, no. 1-35, 2010.

[29] W. J. Randel, F. Wu, and D. J. Gaffen, "Interannual variability of the tropical tropopause derived from radiosonde data and ncep reanalyses," J. Geophys. Res., vol. 105, no. D12, pp. 15509-15523, 2000.

[30] T. Reichler, M. Dameris, and R. Sausen, "Determining the tropopause height from gridded data," Geophys. Res. Lett., vol. 30, no. 20, pp. 1-5, 2003.

[31] T. Schmidt, S. Heise, J. Wickert, G. Beyerle, and C. Reigber, "Gps radio occultation with champ and sac-c: global monitoring of thermal tropopause parameters," Atmos. Chem. Phys., vol. 5, pp. 1473-1488, 2005.

[32] R. A. Craig, The Upper Atmosphere: Meteorology and Physics, vol. 8, Academic Press, 1965.

[33] C. B. Markwardt, "Non-linear least squares fitting in idl with mpfit," in Proc. Astronomical Data Analysis Software and Systems xvii, in ASP Conference Se- 
ries, D. Bohlender, P. Dowler, and D. Durand, Eds., Quebec, Canada, 2008, Astronomical Society of the Pacific: San Francisco, vol. 411, pp. 251-254.

[34] C. Appenzeller, H. C. Davies, and W. A. Norton, "Fragmentation of stratospheric intrusions," J. Geophys. Res., vol. 101, no. D1, pp. 1435-1456, 1996.

[35] E. Palmén, "On the distribution of temperature and wind in the upper westerlies," J. Meteor., vol. 5, pp. 20-27, 1948.

[36] E. F. Danielsen, "The laminar structure of the atmosphere and its relation to the concept of a tropopause," Arch. Met. Geoph. Biokl., vol. A11, pp. 293-332, 1959.

[37] D. J. Seidel and W. J. Randel, "Recent widening of the tropical belt: Evidence from tropopause observations," J. Geophys. Res., vol. 112, no. D20113, pp. 1-6, 2007.

[38] V. Wirth, "Static stability in the extratropical tropopause region," J. Atmos. Sci., vol. 60, pp. 1395-1409, 2003.

[39] S. W. Bell and M. A. Geller, "Tropopause inversion layer: Seasonal and latitudinal variations and representation in standard radiosonde data and global models.," J. Geophys. Res., vol. 113, no. D05109, pp. 1-7, 2008. 


\section{APPENDIX A}

Table I. Statistics of tropopause comparison. The values given are root mean square differences $(\mathrm{m})$, mean differences $(\mathrm{m})$ of GFS - observations and slope $b$ of the least squares fit to a straight line and its $95 \%$ confidence interval for the tropopause height comparisons given in Figure 8. The statistics for the radiosonde comparison exclude those points within the gray ellipse of Figure $8 \mathrm{~b}$.

\begin{tabular}{ccc}
\hline & r.m.s. diff & mean diff \\
\hline GFS-GV & 615 & 6 \\
GFS-Radiosonde & 635 & -75 \\
\hline
\end{tabular}


Table II. Tropopause Characteristics by Latitude

\begin{tabular}{ccc}
\hline Latitude & $\begin{array}{c}\% \text { broad transitions } \\
(\lambda>2 \mathrm{~km})\end{array}$ & $\begin{array}{c}\% \text { high tropopauses } \\
\left(\text { WMO } p_{\text {trop }}<135 \mathrm{hPa}\right)\end{array}$ \\
\hline $25^{\circ}-30^{\circ} \mathrm{N}$ & 57.4 & 72.9 \\
$30^{\circ}-35^{\circ} \mathrm{N}$ & 35.4 & 45.6 \\
$35^{\circ}-40^{\circ} \mathrm{N}$ & 19.5 & 20.9 \\
$40^{\circ}-45^{\circ} \mathrm{N}$ & 8.0 & 5.2 \\
$45^{\circ}-50^{\circ} \mathrm{N}$ & 5.9 & 0.7 \\
\hline
\end{tabular}




\section{APPENDIX B}

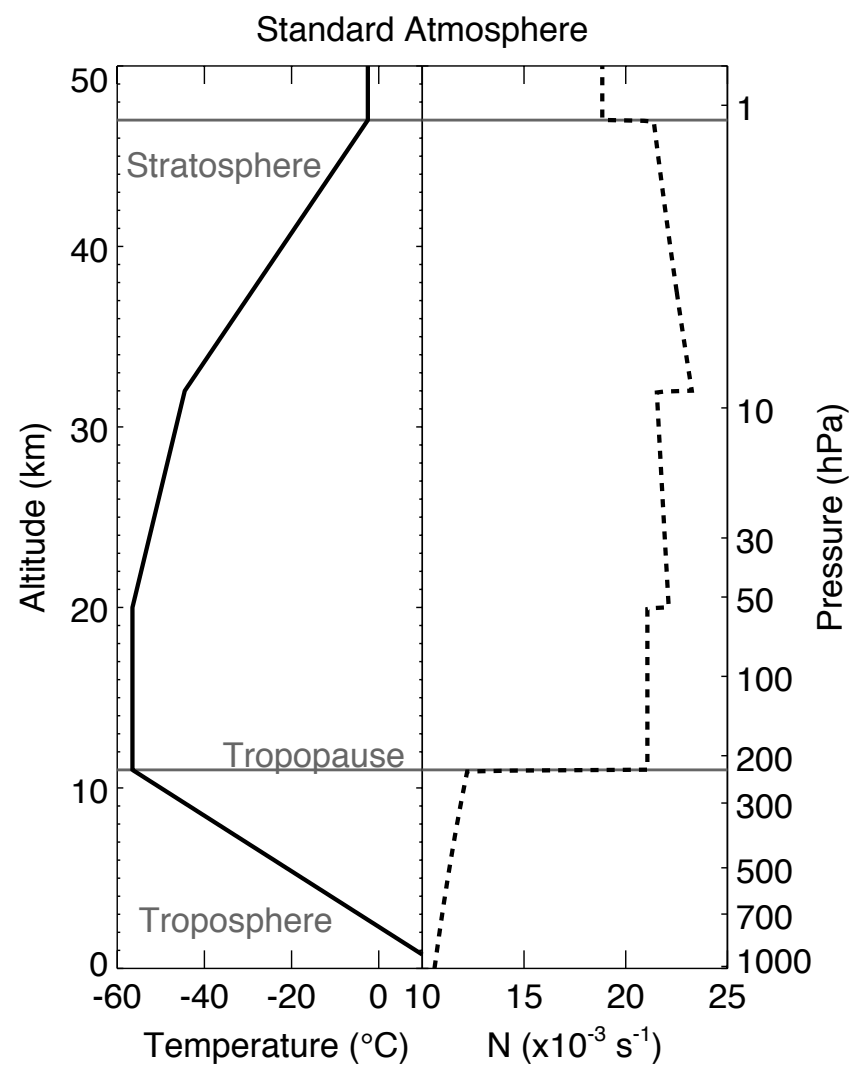

Fig. 1. Data representative of the U.S. Standard Atmosphere. Two profiles are present, temperature (solid) and the Brunt-Väisälä Frequency or static stability $N$ (dashed). 


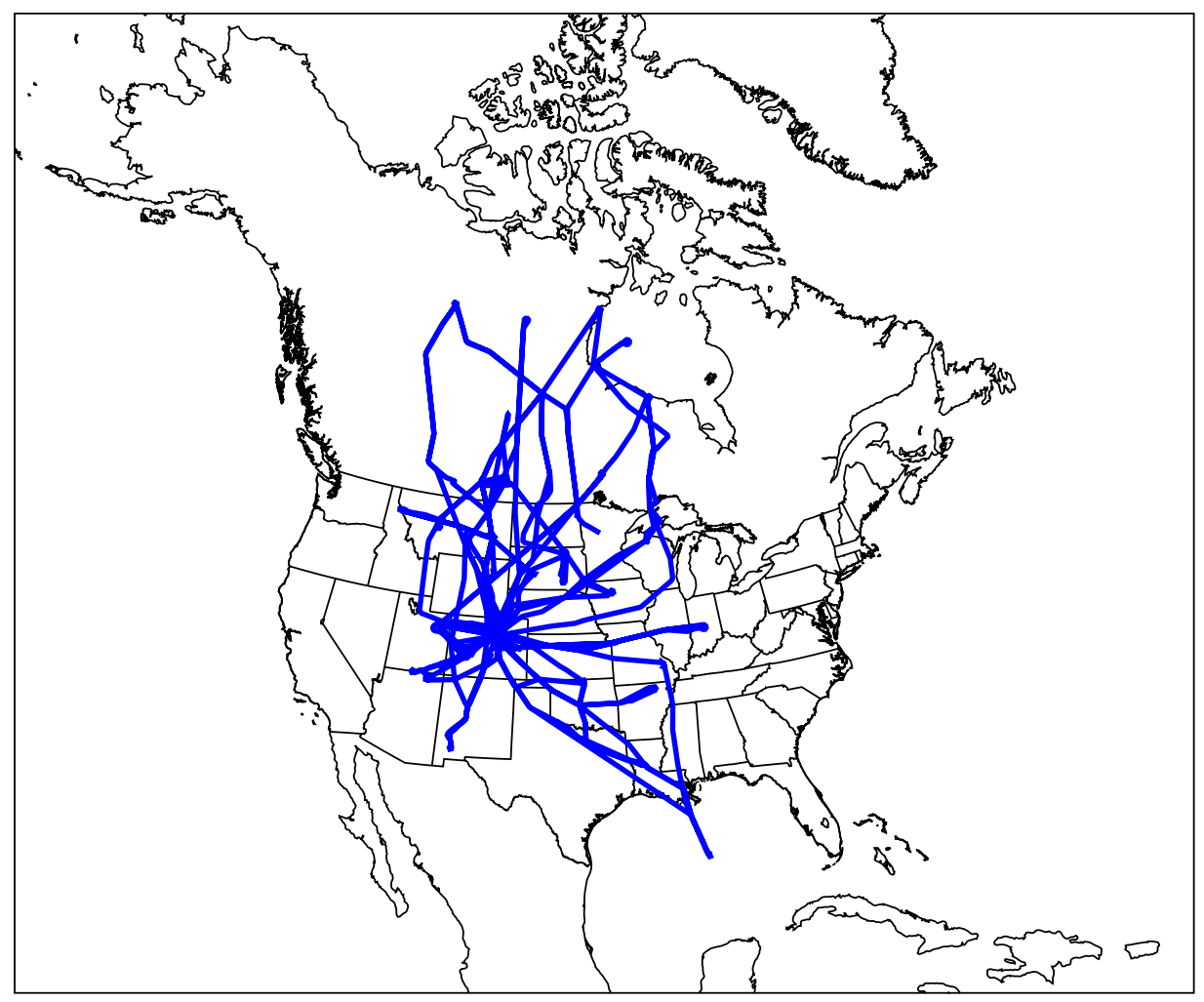

Fig. 2. Map of all 18 START08 flight tracks. 
(a) RF04 20080428T1830 - 1900 UTC

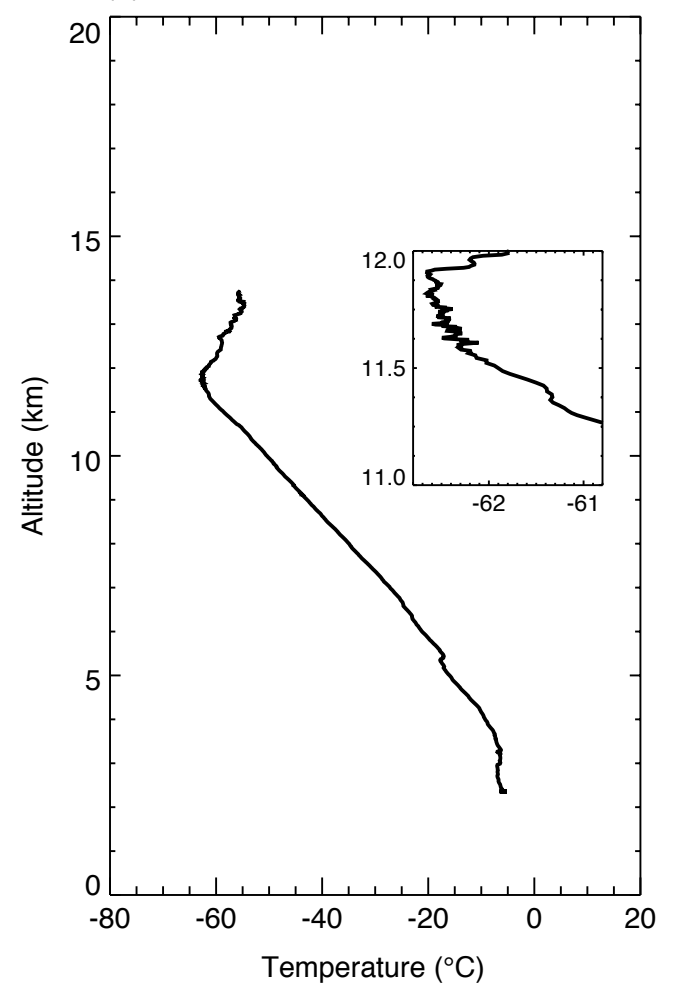

(b) KABR 20080620T00 UTC

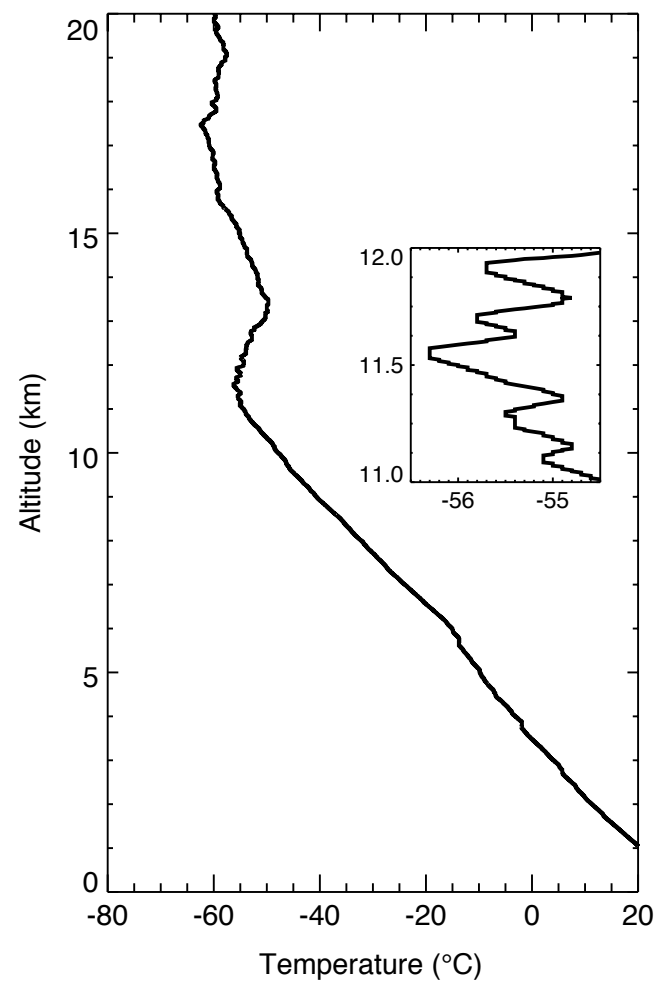

Fig. 3. Sample profiles of temperature for (a) START08 GV aircraft data and (b) radiosonde data. For each profile, an expanded view of the 11-12 km altitude range is given to show characteristics of the data. Profile (a) is from START08 Reasearch Flight 04 (RF04) for the time period 1830-1900 UTC on 2008-04-28. Profile (b) is from KABR (Aberdeen, South Dakota) at 00 UTC on 2008-06-20. 


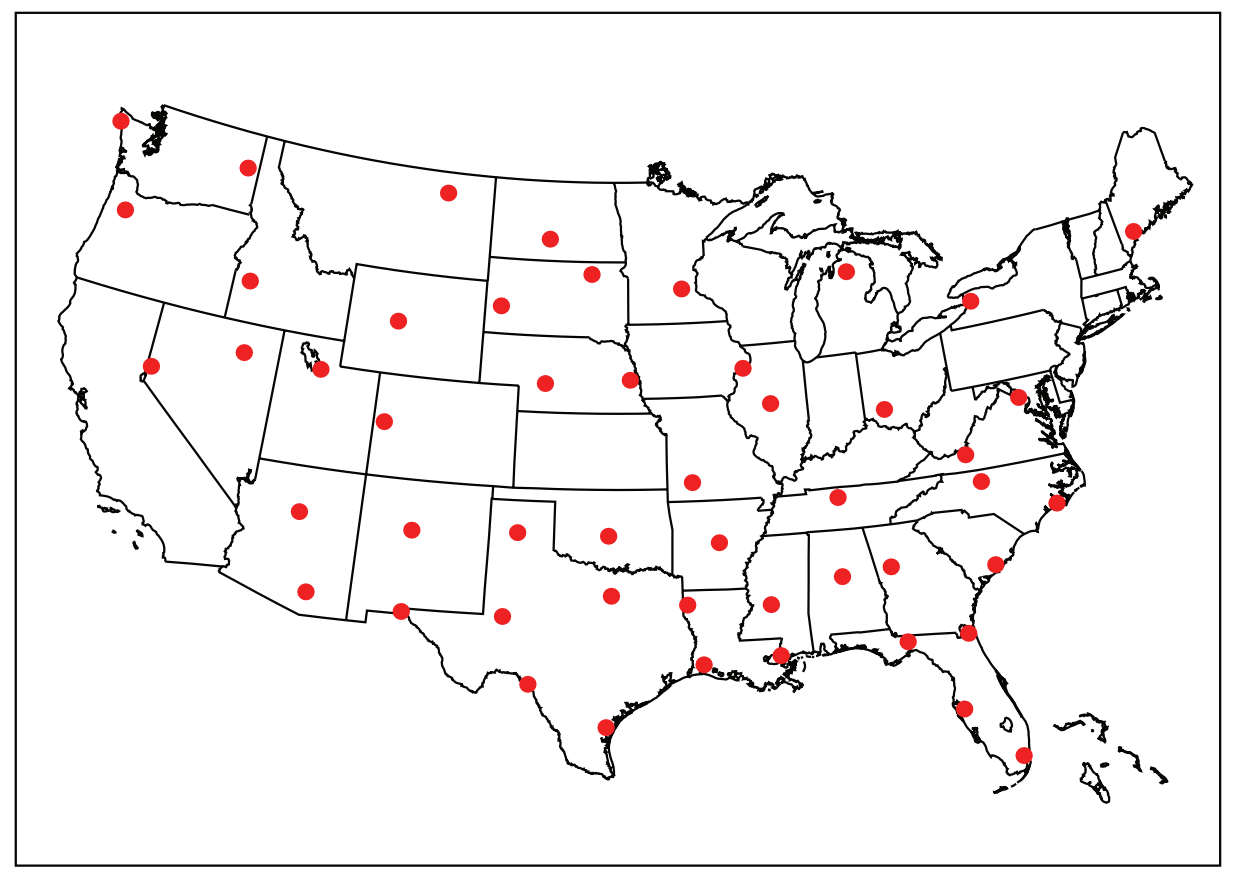

Fig. 4. Map of radiosonde stations used from the continental United States. 

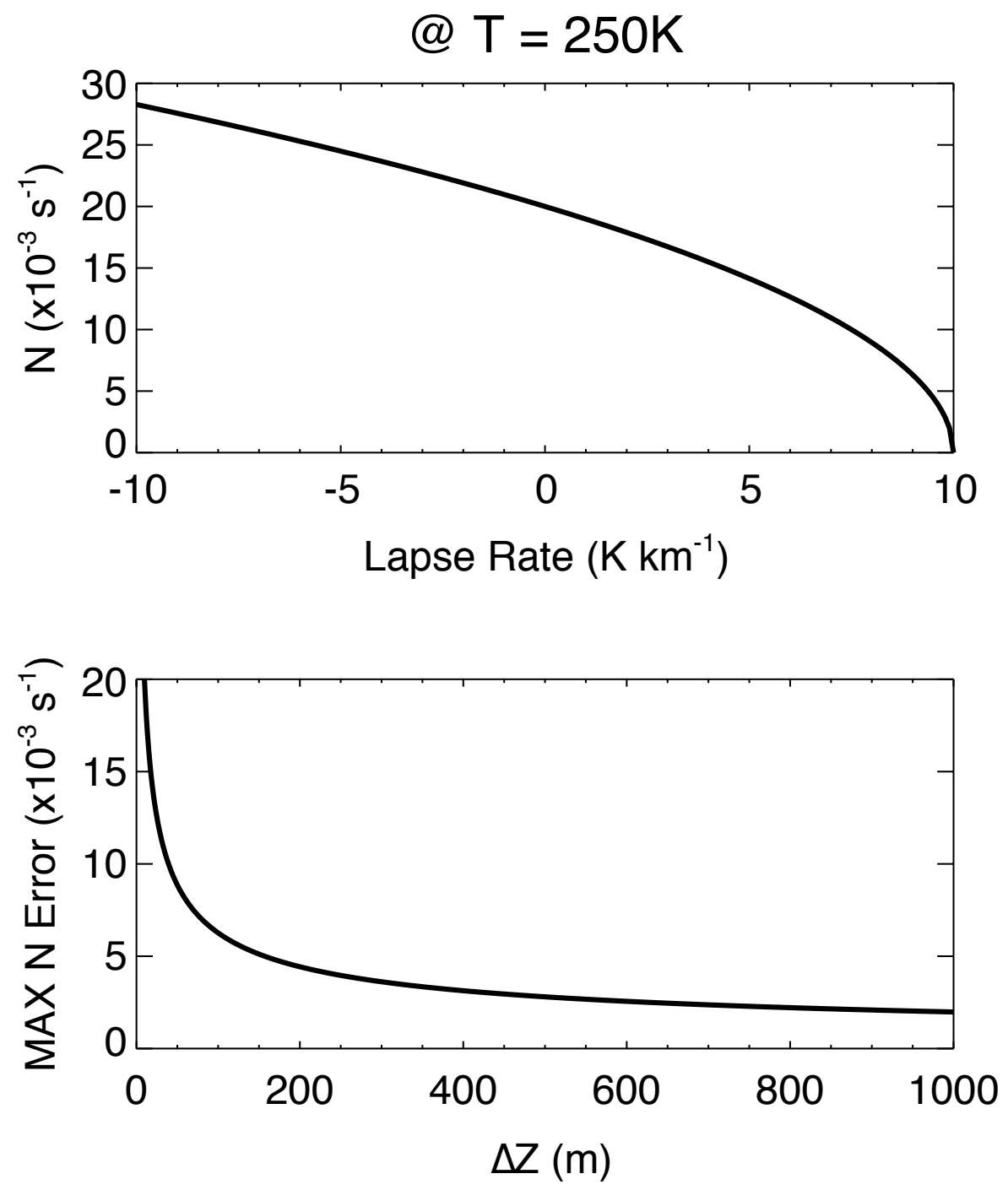

Fig. 5. Assuming an atmospheric temperature of $250 \mathrm{~K}:$ (a) $\mathrm{N}$ as a function of lapse rate and (b) maximum discretization error in $\mathrm{N}$ observed with radiosonde data. 

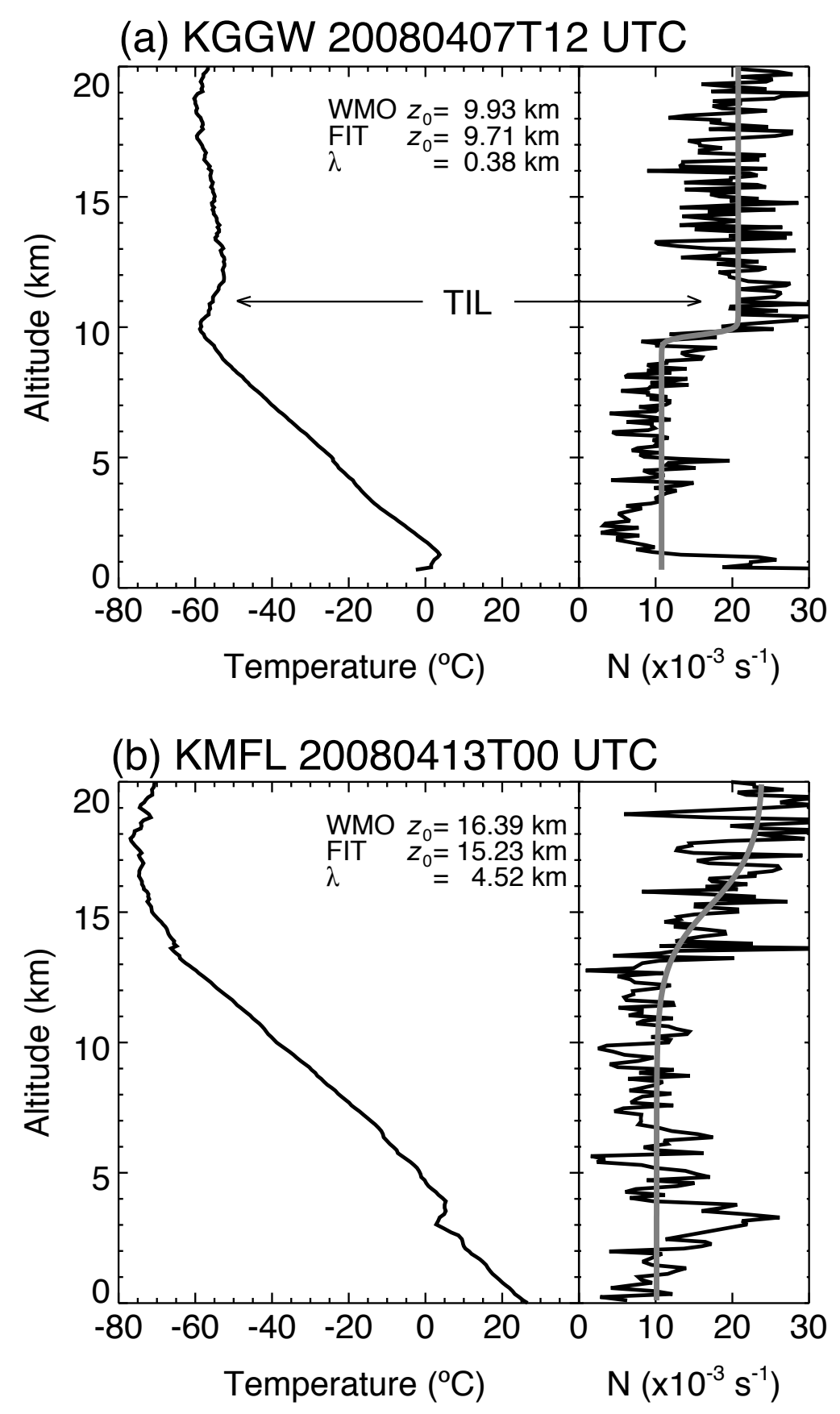

Fig. 6. Two typical atmospheric profiles with temperature (left) and static stability (right) and corresponding hyperbolic tangent curve fits (gray). Profile (a) is an example of a sharp transition from troposphere to stratosphere, while profile (b) is broad. Profile (a) is from KGGW (Glasgow, Montana) and profile (b) is from KMFL (Miami, Florida). Observations are shown at $100 \mathrm{~m}$ sub-sampling. 


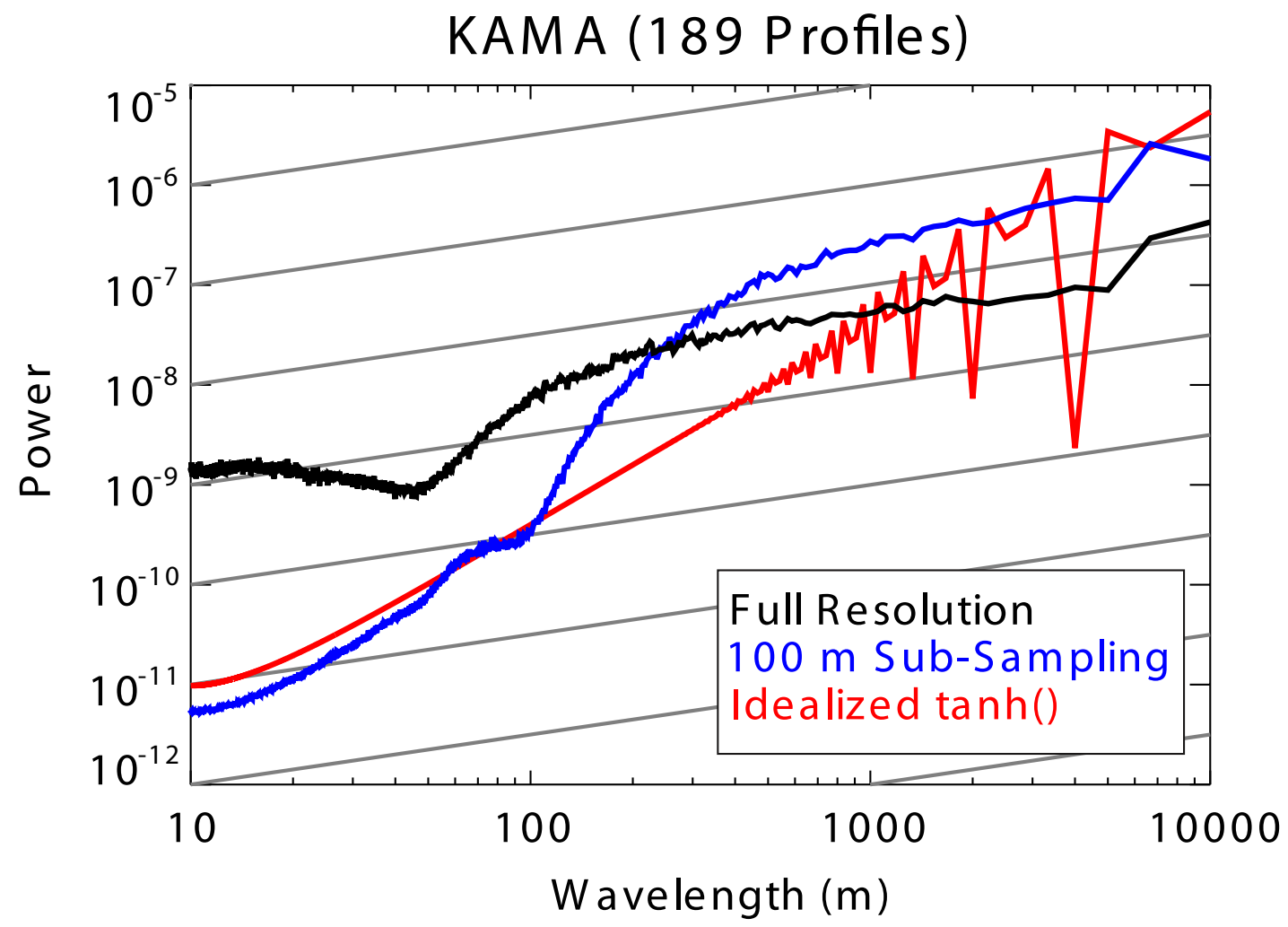

Fig. 7. Average power of Fourier Transforms of static stability $N$ as a function of wavelength for $\sim 200$ soundings from KAMA (Amarillo, TX) at full resolution (black) and $100 \mathrm{~m}$ sub-sampling (blue). The red curve is the power of the transform of a hyperbolic tangent function. The gray lines are 1-to-1 lines. 

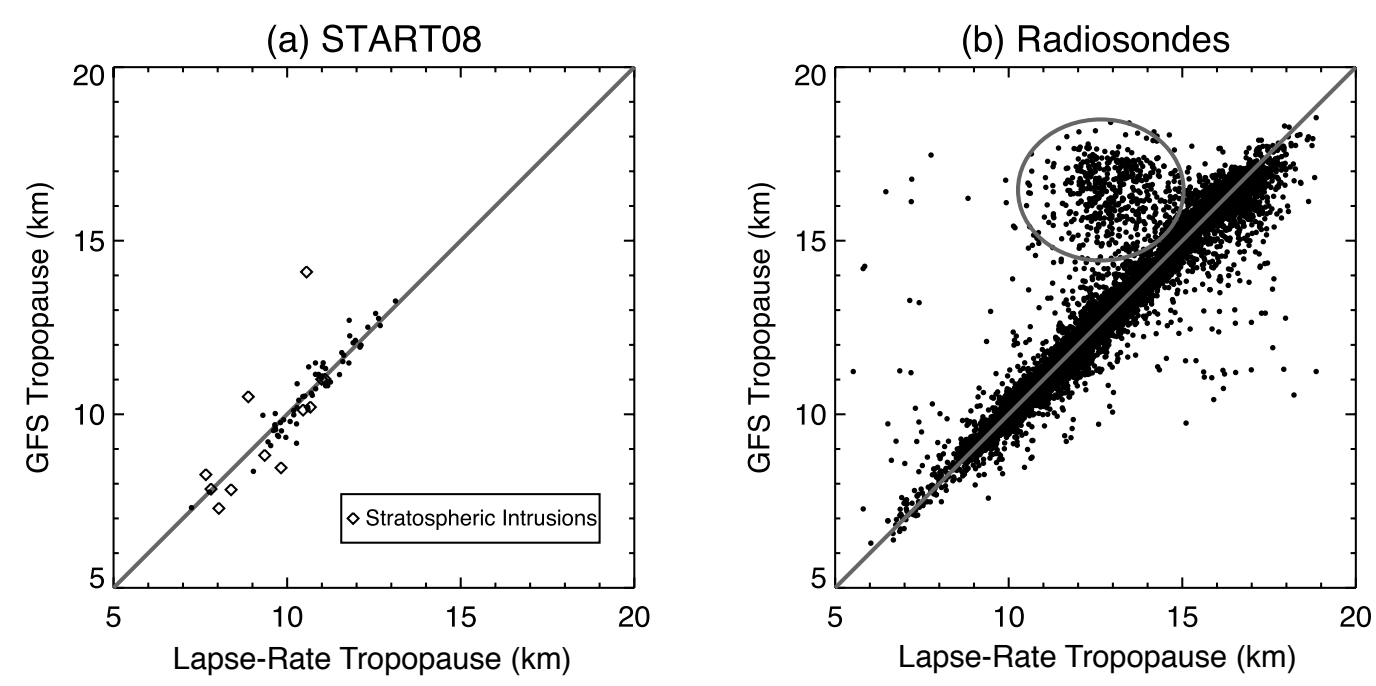

Fig. 8. A scatterplot comparing GFS tropopause heights to observed lapse-rate tropopause heights for (a) START08 aircraft data and (b) Radiosondes. The 1-to-1 line is drawn in gray. For (a), profiles through stratospheric intrusions are marked by diamond plot symbols. For (b), the gray ellipse identifies the population where GFS analysis tropopause heights represent the secondary tropopause rather than primary. 


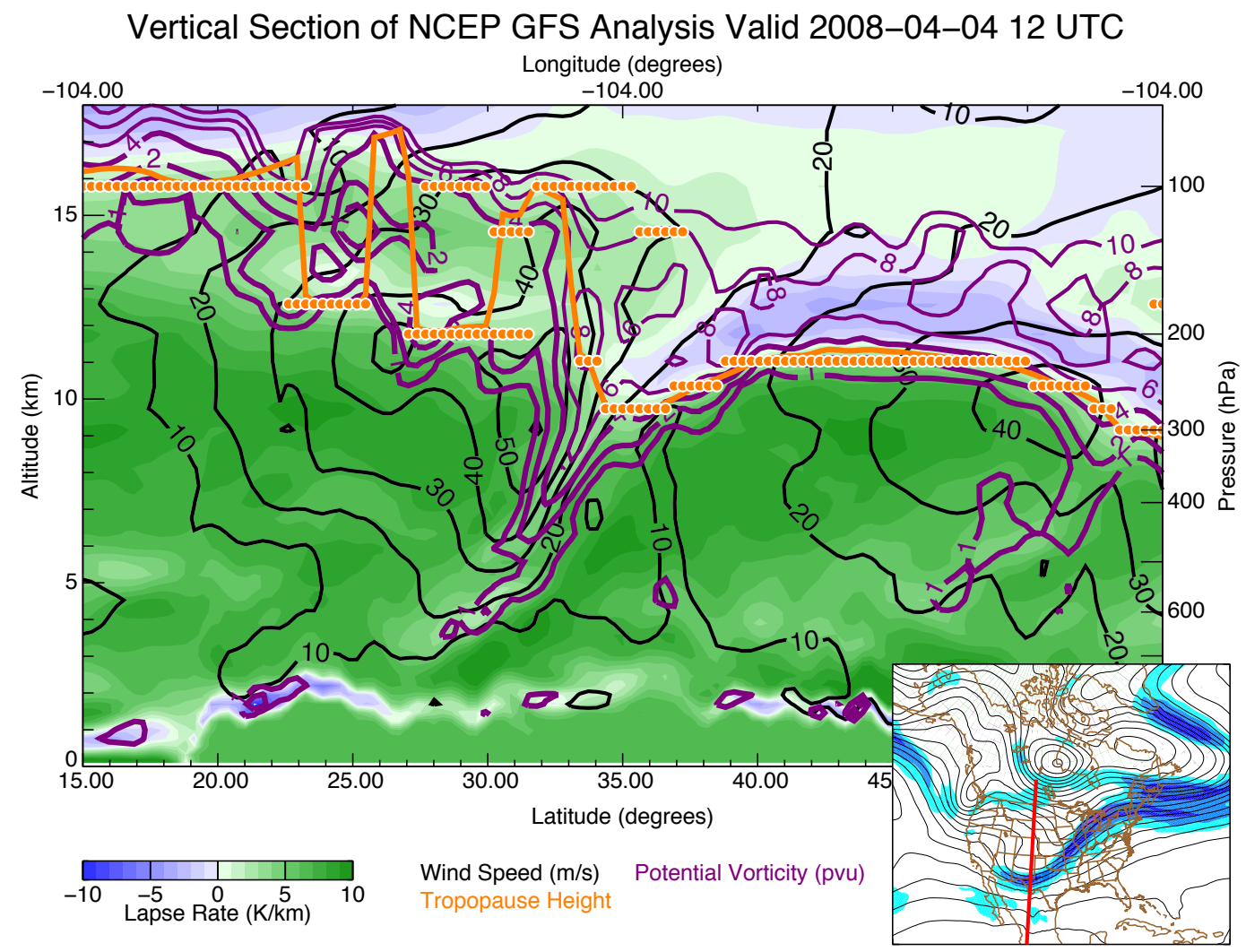

Fig. 9. A vertical section of a GFS volume with corresponding map of the $300 \mathrm{hPa}$ wind field. The red line in the $300 \mathrm{hPa}$ wind map is the location of the section given. In the section, the lapse rate (color-fill) illustrates the thermal structure in the atmosphere; the orange dots represent application of the WMO definition to derive multiple tropopause heights; the orange line is the NCEP GFS output tropopause height calculated on the model grid; the purple contours are lines of constant potential vorticity; the black contours are wind speed and illustrate the vertical structure and extent of the subtropical jet. 


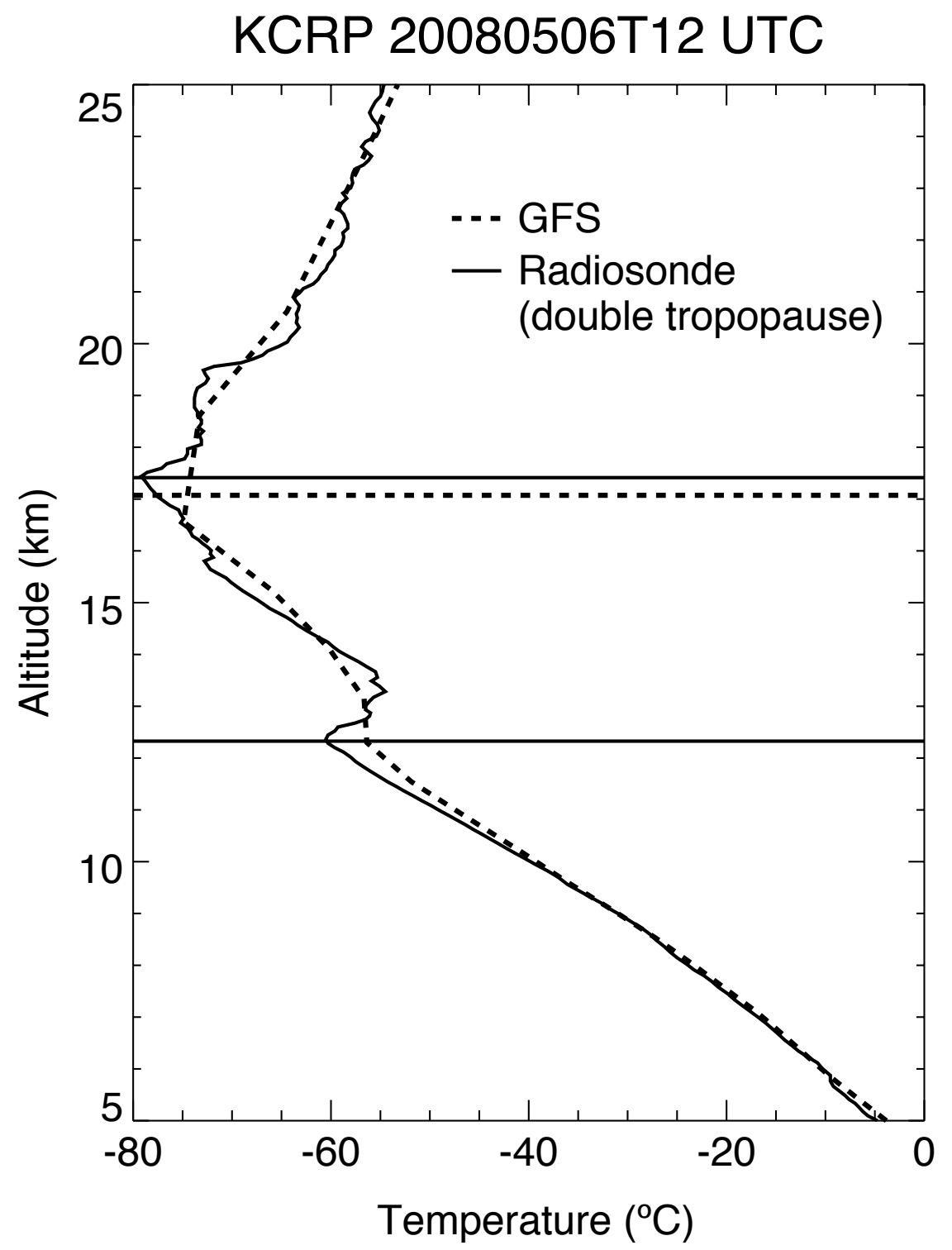

Fig. 10. An example profile from KCRP (Corpus Christi, Texas) where tropopause confusion in the GFS analysis is present. This profile is within the gray ellipse in Figure 8b. The GFS temperature and tropopause interpolated to the sonde location (dashed) and observed temperature and lapse-rate tropopauses (solid) are given. 


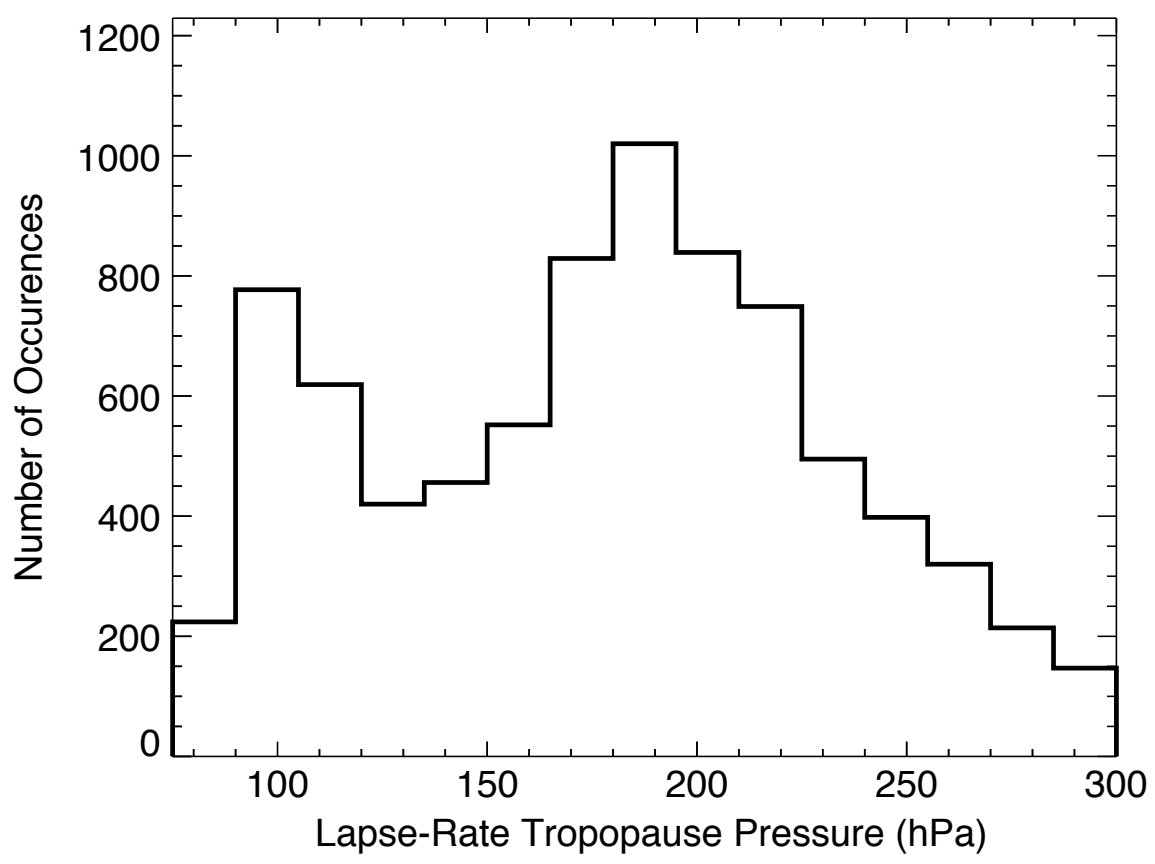

Fig. 11. Distribution of lapse-rate tropopause pressure for all radiosondes. 


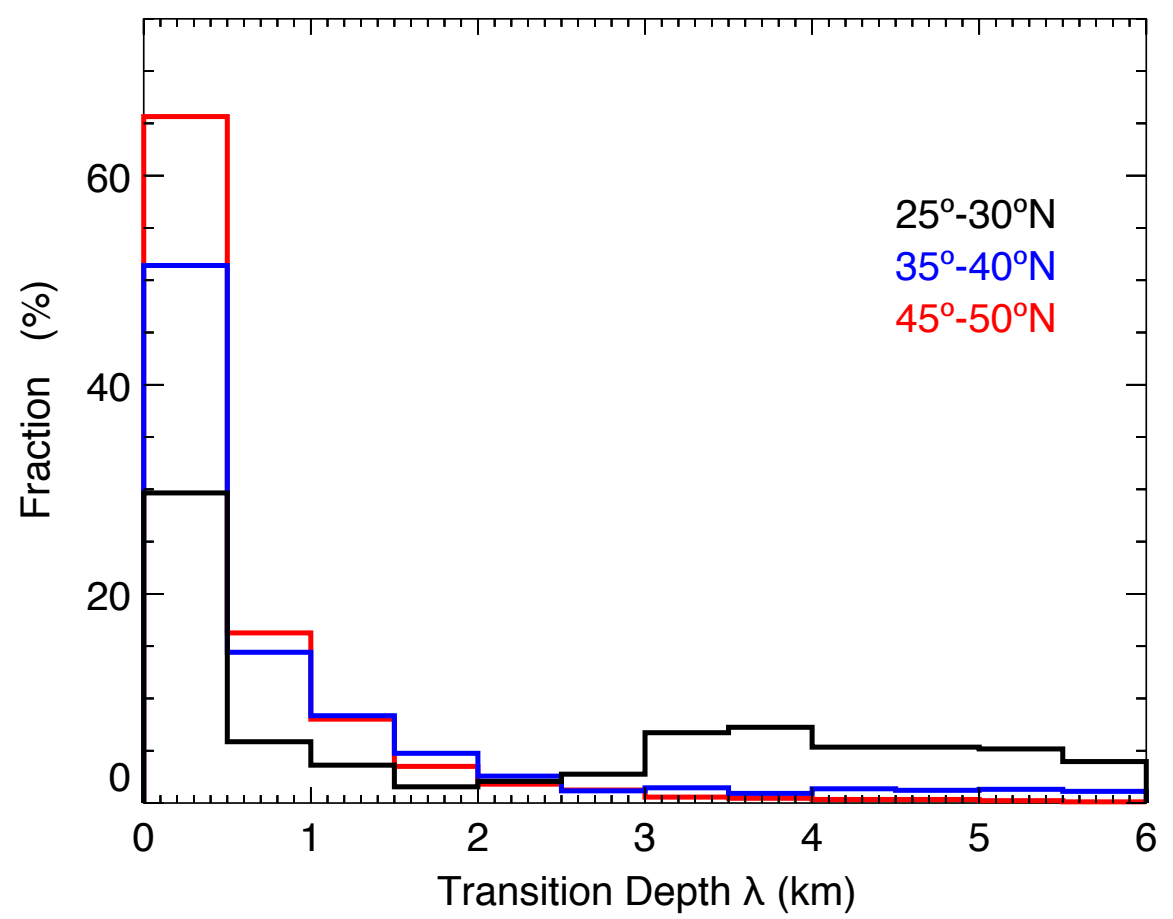

Fig. 12. Fraction of transition depths $\lambda$ in three latitude bands. 


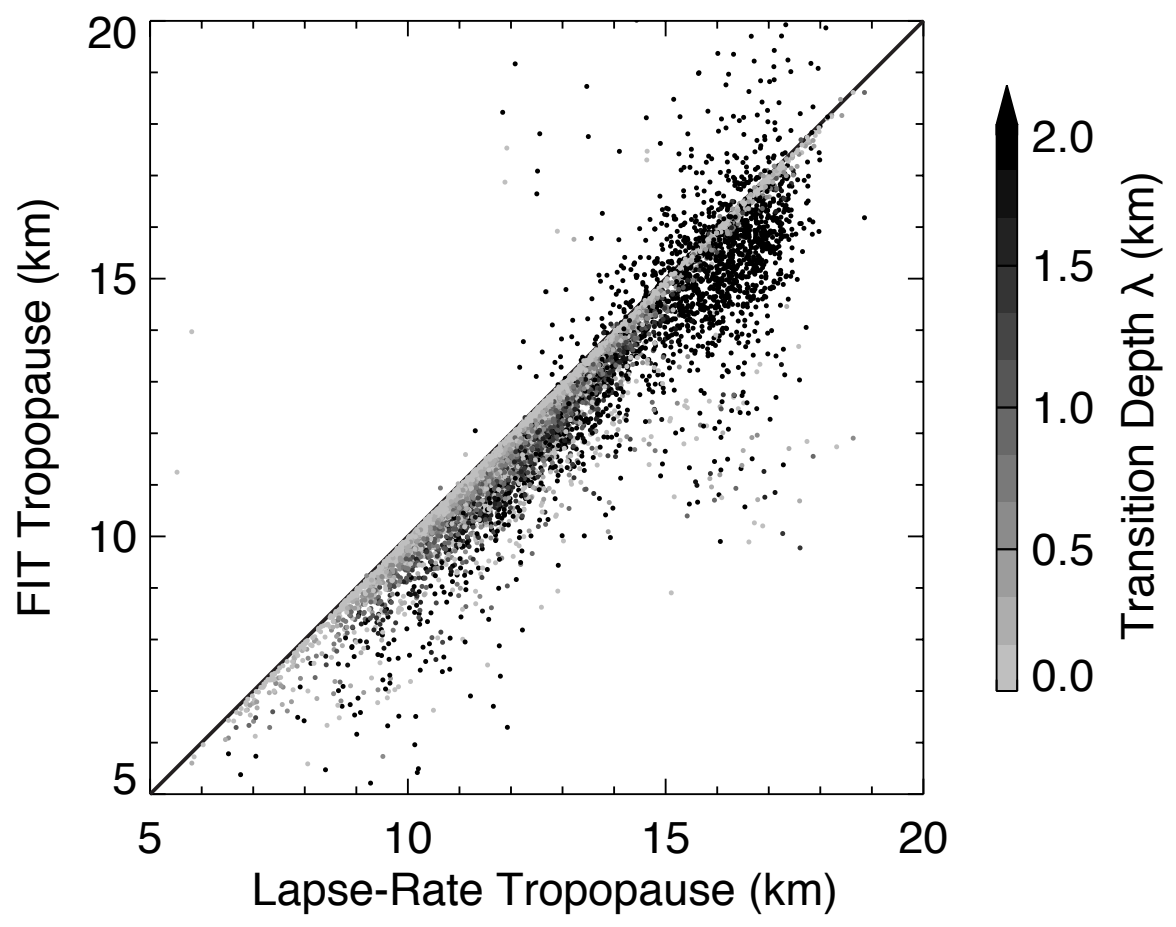

Fig. 13. A scatterplot comparing the curve-fit tropopause and WMO lapse-rate tropopause heights for all radiosondes. The 1-to-1 line is drawn in black. Points are colored by the transition depth $\lambda$. 


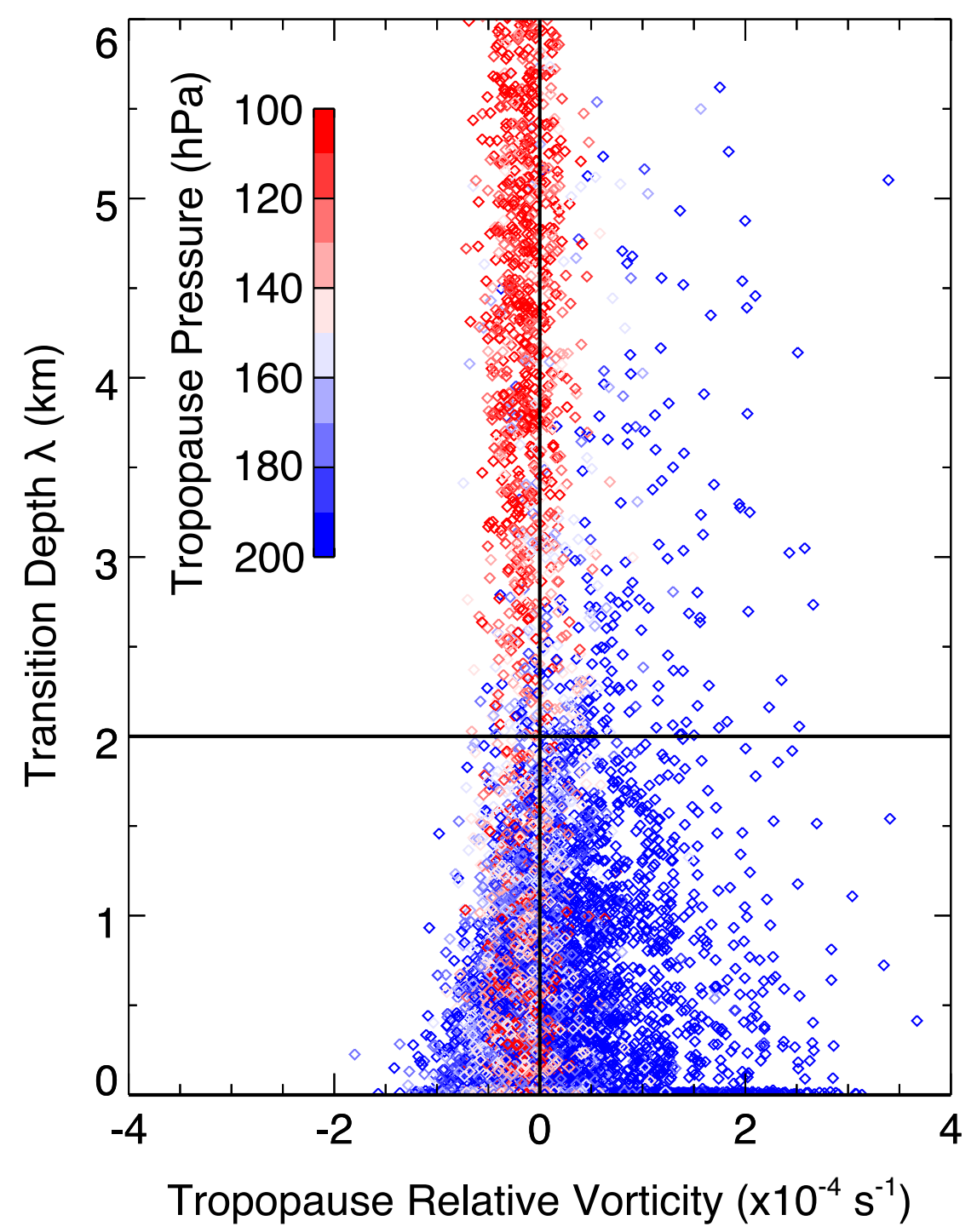

Fig. 14. Transition depth $\lambda$ as a function of lapse-rate tropopause relative vorticity for all radiosondes. Points are colored by lapse-rate tropopause pressure. The black horizontal line indicates the division between large and small transition depths. 

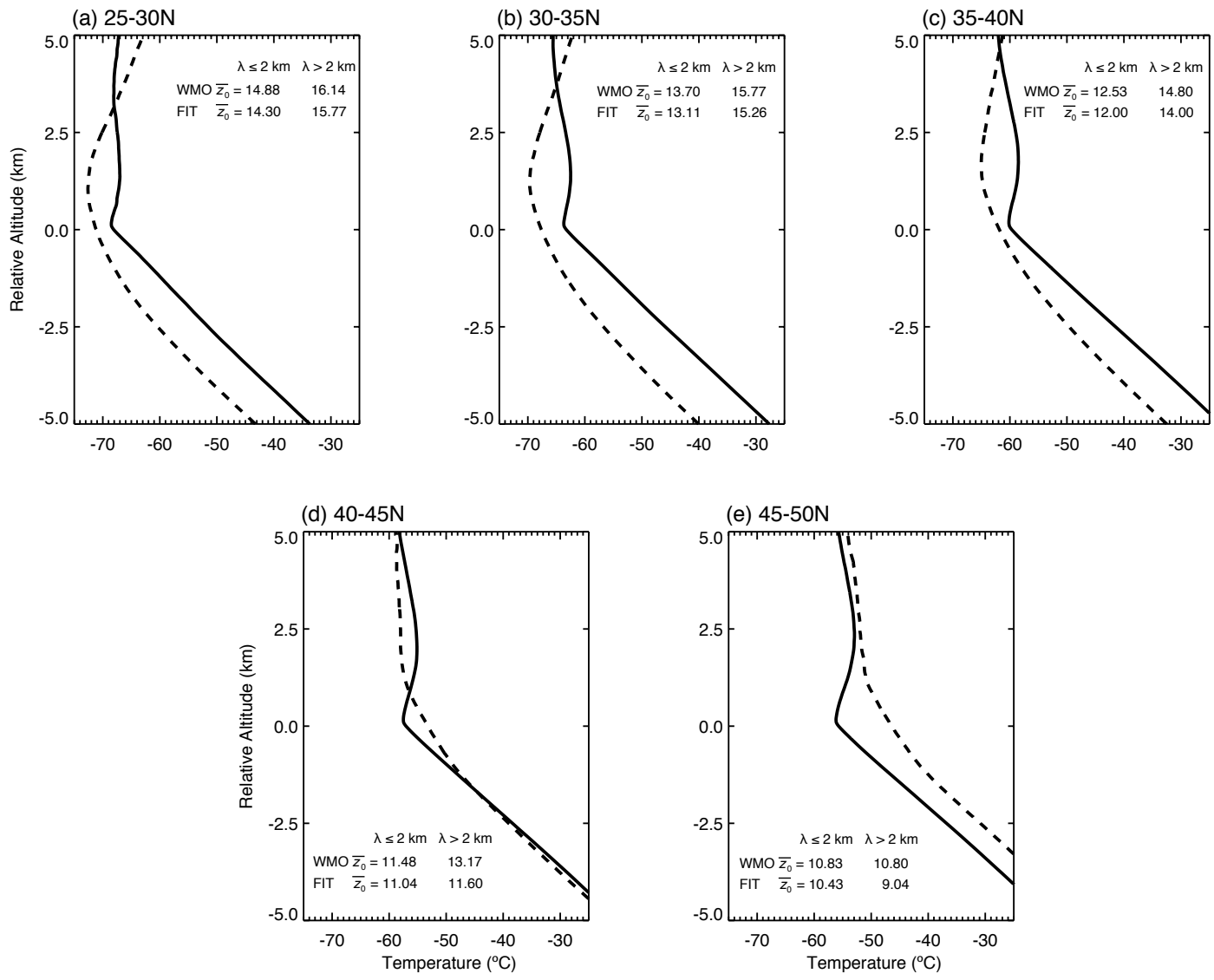

Fig. 15. Average temperature for $5^{\circ}$ wide latitude bands at relative altitude to the curve-fit tropopause. Two profiles for each band illustrate averages for large $(>2 \mathrm{~km}$, dashed) and small $(\leq 2 \mathrm{~km}$, solid) transition depths $(\lambda)$. The average lapse-rate and curve-fit tropopauses for large and small transition depths are also given in each plot. 


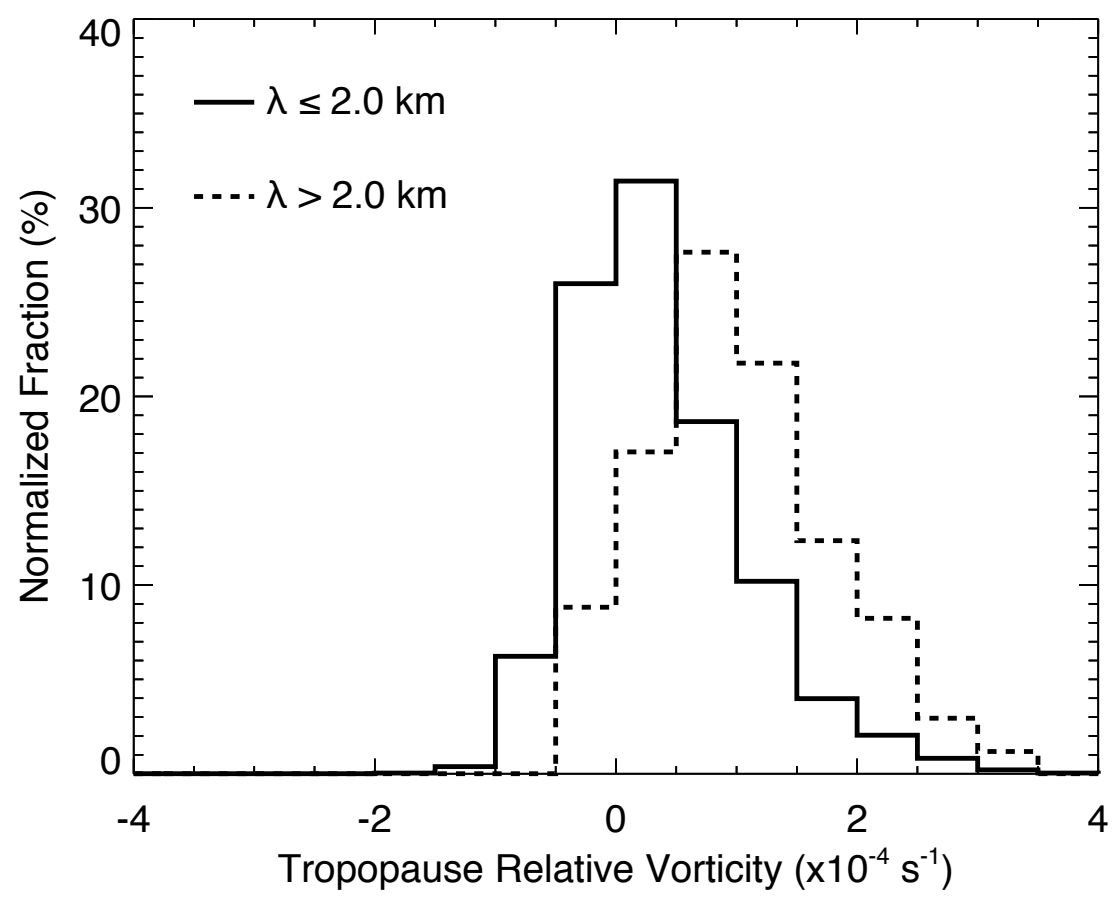

Fig. 16. Normalized fraction of tropopause relative vorticity for large $(\lambda>2 \mathrm{~km}$, dashed) and small ( $\lambda \leq 2 \mathrm{~km}$, solid) transition depths for all radiosondes with lapse-rate tropopause pressure $p_{\text {trop }} \geq 200 \mathrm{hPa}$. 


\section{VITA}

Cameron Ross Homeyer

Department of Atmospheric Sciences

Texas A\&M University

3150 TAMU

College Station, TX 77843-3150

B.S., Meteorology, 2008, Texas A\&M University

M.S., Atmospheric Sciences, 2010, Texas A\&M University 